Center for

Mathematical Economics

Working Papers

February 2014

\title{
Wage Bargaining, Employment, and Union Power: The Right-to-Manage Approach
}

Volker Böhm and Oliver Claas

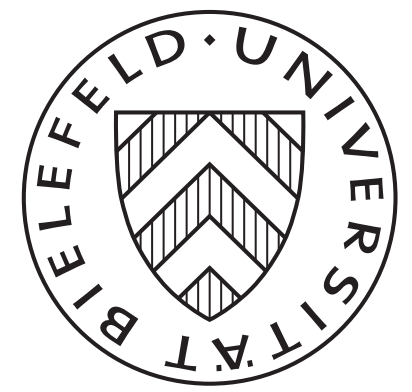




\title{
Wage Bargaining, Employment, and Union Power: The Right-to-Manage Approach
}

\author{
Volker Böhm* Oliver Claas ${ }^{\dagger}$
}

February 4, 2014

\begin{abstract}
This paper analyzes the implications of right-to-manage wage bargaining between a producers' syndicate and a workers' union representing finite numbers of identical members in a monetary macroeconomic model of the AS-AD type with government activity. At given prices and price expectations, nominal wages are set according to a Nash bargaining agreement. Producers then choose labor demand and commodity supply to maximize profits at given output prices. The commodity market clears in a competitive fashion. Unique temporary equilibria are shown to exist for each level of relative power of the union. These equilibria may exhibit under- or overemployment, depending on the level of union power.

The paper presents a complete comparative-statics analysis of the temporary equilibrium, in particular of the role of union power on employment, wages, and income distribution, including a variety of different qualitative features compared to the situation under efficient bargaining. These differences arise primarily from a supply-side effect of union power under the right-to-manage approach as compared to a demand-side effect under efficient bargaining.

In addition, the dynamic evolution under perfect foresight is monotonic with two coexisting balanced steady states, one of which is stable under certain conditions. These properties are qualitatively identical to those under efficient bargaining or under perfect competition.
\end{abstract}

Keywords: Collective Bargaining, Nash Bargaining, Union Power, Aggregate Supply-Aggregate Demand, Government Deficits, Perfect Foresight, Dynamics, Stability

JEL Classification: C78, D61, E24, E25, E31, E42, J52

*Department of Economics, Bielefeld University, vboehm@wiwi.uni-bielefeld.de

${ }^{\dagger}$ Center for Mathematical Economics (IMW) and Bielefeld Graduate School of Economics and Management (BiGSEM), Bielefeld University, oliver.claas@uni-bielefeld.de. This research was carried out within the International Research Training Group "Economic Behavior and Interaction Models" (EBIM) financed by the German Research Foundation (DFG) under contract GRK 1134/2. Financial support by the IMW is gratefully acknowledged. 


\section{Contents}

1 Introduction $\quad 3$

2 Nash Bargaining under Right to Manage 4

3 Wage Bargaining and Employment $\quad 6$

4 Employment in Temporary Equilibrium $\quad 9$

4.1 Aggregate Supply and Aggregate Demand . . . . . . . . . . . . . . . . . 9

4.2 Properties of the Equilibrium Mappings . . . . . . . . . . . . . . . . 11

4.3 A Parametric Example: the Isoelastic Case . . . . . . . . . . . . . . . . . . . . 16

$\begin{array}{llr}5 & \text { Union Power and the Macroeconomy } & 18\end{array}$

6 Dynamics of Monetary Equilibrium under Perfect Foresight 22

$\begin{array}{llr}7 & \text { Summary and Conclusion } & 26\end{array}$

$\begin{array}{lr}\text { A Proofs } & 27\end{array}$

A.1 Convexity of the Set of Feasible Payoffs . . . . . . . . . . . . . . . 27

A.2 Proof of Lemma 3.1 . . . . . . . . . . . . . . . . . . . . 28

B Calculations Parametric Example - the Isoelastic Case 29

B.1 Comparative Statics . . . . . . . . . . . . . . . . 31

$\begin{array}{ll}\text { Bibliography } & 33\end{array}$ 


\section{Introduction}

In most (Western) economies, bargaining between workers' unions and producers' syndicates about the wage level is a regular and re-occuring phenomenon, which induces an endogenous mechanism determining the wage rate and the level of employment in a noncompetitive fashion. It is sometimes argued that high union power is beneficial to workers and that it increases the level of employment, in particular when bargaining occurs over employment and wages simultaneously.

Theoretical models on wage bargaining between a union and a producers' syndicate using bargaining solutions à la Nash $(1950,1953)$ can be divided into two strands, depending on whether the employment level is subject of the bargain or not. The first class of models, in which wage and employment levels are determined simultaneously by the negotiating parties, are the efficient bargaining models (see, for example, McDonald \& Solow 1981; Blanchard \& Fischer 1993; Booth 1996). In these models, the rents from trading are efficiently shared between the agents. The second class consists of models with wage bargaining only. Since the producer retains the right to choose the size of the workforce once the wage has been set, it is called the right-to-manage approach. A special case is the monopoly union model, in which the union unilaterally sets the wage rate and the producer subsequently picks the employment level.

Supporters of efficient bargaining argue that right-to-manage bargaining leads to inefficiencies as pointed out by Leontief (1946) because potential gains from trade remain unused by agents who otherwise are assumed to behave rationally. Efficient agreements, however, are rarely observed empirically and their positive implications are often contested (Layard, Nickell \& Jackman 2009; Layard \& Nickell 1990). It is often unclear whether the different results for the two bargaining scenarios arise from specific assumptions about the bargaining structure used in the labor market or whether they stem from the neglect of general-equilibrium effects, which are ignored in many partial-equilibrium presentations. Other reasons are related to the fact that a union may represent only those who are already employed and not the workers to be hired in the future, and that layoffs only affect a relatively small number of workers in a pre-assigned order (e.g. according to seniority). Therefore, the workers' objective is not the aggregate size of employment. Enforcing efficient bargaining agreements in a producers' syndicate with potentially heterogeneous members is a further issue that prevents a wage-employment iunctim in practice. Surprisingly few contributions to the literature work out the full general-equilibrium effects of their partial-equilibrium models. More importantly, however, they rarely discuss these features within a dynamic monetary macro model.

Starting from the AS-AD model with competitive markets, Böhm \& Claas (2012) provides a micro-founded closed-economy AS-AD model with efficient bargaining on the labor market while the commodity market clears competitively. This paper embeds the right-to-manage wage bargaining approach into the AS-AD framework in a similar fashion. Section 2 and Section 3 lay out the microeconomic foundations of all agents in the economy and model the labor market with right-to-manage wage bargaining between a union and a producers' syndicate under full unionization. Section 4 closes the economy and analyzes the comparative-statics properties in full general equilibrium for the macroeconomy. Section 5 compares the right-to-manage model developed in the first part of the paper with the competitive one and the efficient-bargaining model. Section 6 analyzes the dynamic evolution of the economy and its stability under perfect foresight. Section 7 concludes. 


\section{Nash Bargaining under Right to Manage}

\section{The Public Sector}

The public sector consists of a government and a central bank. The government demands $g \geq 0$ units of the (homogenous) good produced and finances its spendings by levying proportional taxes $0 \leq \tau_{\pi} \leq 1$ on profit income resp. $0 \leq \tau_{w} \leq 1$ on wage income. This implies that, in general, the government's budget is not balanced. The central bank creates resp. destroys money, which is the only intertemporal store of value for consumers, accordingly.

\section{The Production Sector}

The production sector is made up of $n_{f} \geq 1$ homogeneous, profit-maximizing firms which produce from labor the same nonstorable good to be sold on the competitive commodity market. Each firm has the twice continously differentiable, strictly monotonically increasing, strictly concave, and invertible production function $F: \mathbb{R}_{+} \rightarrow \mathbb{R}_{+}, z \mapsto F(z), F(0)=0$, which is assumed to satisfy the Inada conditions, i. e.

$$
\lim _{z \rightarrow 0} F^{\prime}(z)=\infty \quad \text { and } \quad \lim _{z \rightarrow \infty} F^{\prime}(z)=0 .
$$

For a given a commodity price $p$, a wage rate $w$, and an employment level $z \geq 0$, short-run profits are given by $\Pi(p, w, z):=p F(z)-w z$, which are paid entirely to the owners/shareholders of the firm. The labor demand by a typical firm under competition is

$$
h_{\mathrm{com}}\left(\frac{w}{p}\right):=\arg \max _{z \geq 0}\{p F(z)-w z\}=\left(F^{\prime}\right)^{-1}\left(\frac{w}{p}\right)
$$

which is a strictly monotonically decreasing function of the real wage $w / p$. In noncompetitive situations, the firm only hires workers if production leads to a nonnegative profit $\Pi(p, w, z)=$ $p F(z)-w z \geq 0$. This constitutes the firms' participation constraint and defines the reservation wage

$$
W_{\Pi}(p, z):=p \frac{F(z)}{z},
$$

which is the maximum wage the firm is willing to pay while producing.

\section{The Consumption Sector}

The consumption sector consists of overlapping generations of two types of consumers $-n_{s}$ homogeneous shareholders and $n_{w}$ homogeneous workers -, who all live for two consecutive periods. Every consumer receives income only when young, i. e. all second-period consumption has to be financed by savings. The future commodity price $p^{e}>0$ is given as a point forecast at the beginning of the period and is the same for all consumers.

The young shareholders receive net profits of the firms. Their consumption-savings decision is based on a homothetic utility function so that their propensity to consume $0 \leq c\left(\theta^{e}\right) \leq 1$ is a function of the expected rate of inflation $\theta^{e}:=p^{e} / p$ only. 
Every worker receives income only from working when young, which he saves entirely. His intertemporal utility for labor $\ell \geq 0$ and future consumption $c^{e} \geq 0$ is given by an additively separable indirect utility function $u: \mathbb{R}_{+}^{2} \rightarrow \mathbb{R}_{+}$with $u\left(\ell, c^{e}\right):=c^{e}-v(\ell)$ where $v: \mathbb{R}_{+} \rightarrow \mathbb{R}_{+}$ measures the disutility from labor. ${ }^{1}$ The function $v$ is assumed to be continuously differentiable, strictly monotonically increasing, strictly convex, and invertible, and it satisfies $v^{\prime}(0)=0$ as well as $\lim _{\ell \rightarrow \infty} v^{\prime}(\ell)=\infty$. Under competitive conditions, the utility-maximizing labor supply is

$$
\arg \max _{\ell \geq 0}\left\{u\left(\ell,\left(1-\tau_{w}\right) \frac{w}{p^{e}} \ell\right)\right\}=\left(v^{\prime}\right)^{-1}\left(\left(1-\tau_{w}\right) \frac{w}{p^{e}}\right),
$$

which is globally defined and invertible since $v$ is strictly convex and satiesfies the Inada conditions. Since any positive level of work induces disutility, his utility function implies a participation constraint

$$
u(0,0)=0 \leq u\left(\ell,\left(1-\tau_{w}\right) \frac{w}{p^{e}} \ell\right)=\left(1-\tau_{w}\right) \frac{w}{p^{e}} \ell-v(\ell),
$$

i. e. a pair of positive labor supply and future consumption must be at least as good as not working. Solving for $w / p^{e}$ yields the individual reservation wage as a function of the amount of labor $\ell$

$$
\frac{w}{p^{e}}=\frac{1}{1-\tau_{w}} \frac{v(\ell)}{\ell}
$$

which is the minimal wage below which he is not willing to work the amount $\ell$.

With $n_{w}$ workers, the aggregate competitive labor supply is given by

$$
N_{\text {com }}\left(\frac{w}{p^{e}}\right)=n_{w} \ell=n_{w}\left(v^{\prime}\right)^{-1}\left(\left(1-\tau_{w}\right) \frac{w}{p^{e}}\right),
$$

which has a global inverse

$$
\frac{w}{p^{e}}=S_{\mathrm{com}}(L):=\frac{1}{1-\tau_{w}} v^{\prime}\left(\frac{L}{n_{w}}\right)
$$

under the assumption that all $n_{w}$ workers are treated equally on the labor market. Similarly, the aggregate reservation wage is given by

$$
\frac{w}{p^{e}}=S(L):=\frac{n_{w}}{L\left(1-\tau_{w}\right)} v\left(\frac{L}{n_{w}}\right) .
$$

Therefore,

$$
W_{\Omega}\left(p^{e}, L\right):=p^{e} S(L)
$$

constitutes the aggregate participation constraint in nominal terms. Due to the properties of $v$, the aggregate reservation wage is a strictly increasing function of the aggregate employment level with well-defined inverse $N: \mathbb{R}_{+} \rightarrow \mathbb{R}_{+}$, mapping the expected real wage $w / p^{e}$ into an employment level $N\left(w / p^{e}\right)$. This function also is strictly monotonically increasing with full range.

\footnotetext{
${ }^{1}$ Assuming intertemporal consumption to be homothetic (as in the case of the shareholders) allows for a generalized consumption-savings behavior.
} 


\section{$3 \quad$ Wage Bargaining and Employment}

The entire work force is assumed to be represented by a union which negotiates a uniform wage rate for all its members, maximizing the aggregate excess wage bill

$$
\Omega\left(p^{e}, w, L\right):=w L-p^{e} S(L) L=\left(w-W_{\Omega}\left(p^{e}, L\right)\right) L .
$$

The union is engaged in a Nash bargain with all firms simultaneously (or with an employers' union) over the wage rate only; the employment decision is then left the firms (the so-called right to manage of the firm). Thus, the bargaining procedure is a two-stage game. In the first stage, the bargaining parties agree on a wage rate for given levels of employment, prices, and price expectations. In the second stage, every firm chooses a profit-maximizing level of employment equal to $h_{\mathrm{com}}(w / p)$. As is customary in such models, the relative bargaining power of the union is given by a number $0 \leq \lambda \leq 1$ while the firms are endowed with bargaining power $1-\lambda$. Since this behavior is anticipated by the bargaining parties, the game is solved by backward induction. The bargaining wage is therefore such that it maximizes

$$
\begin{aligned}
& N P(w, L, \lambda) \quad \text { subject to } \\
& \Omega\left(p^{e}, w, L\right) \geq 0 \quad \text { and } \quad L=n_{f} h_{\text {com }}(w / p)
\end{aligned}
$$

where

$$
\begin{aligned}
N P(w, L, \lambda) & :=\left(n_{f} \Pi\left(p, w, \frac{L}{n_{f}}\right)\right)^{1-\lambda}\left(\Omega\left(p^{e}, w, L\right)\right)^{\lambda} \\
& =(\underbrace{n_{f} p F\left(\frac{L}{n_{f}}\right)-w L}_{\text {agg. profits - employers' union }})^{1-\lambda}(\underbrace{w L-p^{e} S(L) L}_{\text {agg. excess wage bill }})^{\lambda}
\end{aligned}
$$

is the asymmetric Nash product. Figure 1 displays the set of feasible payoffs and one level curve of the asymmetric Nash product.

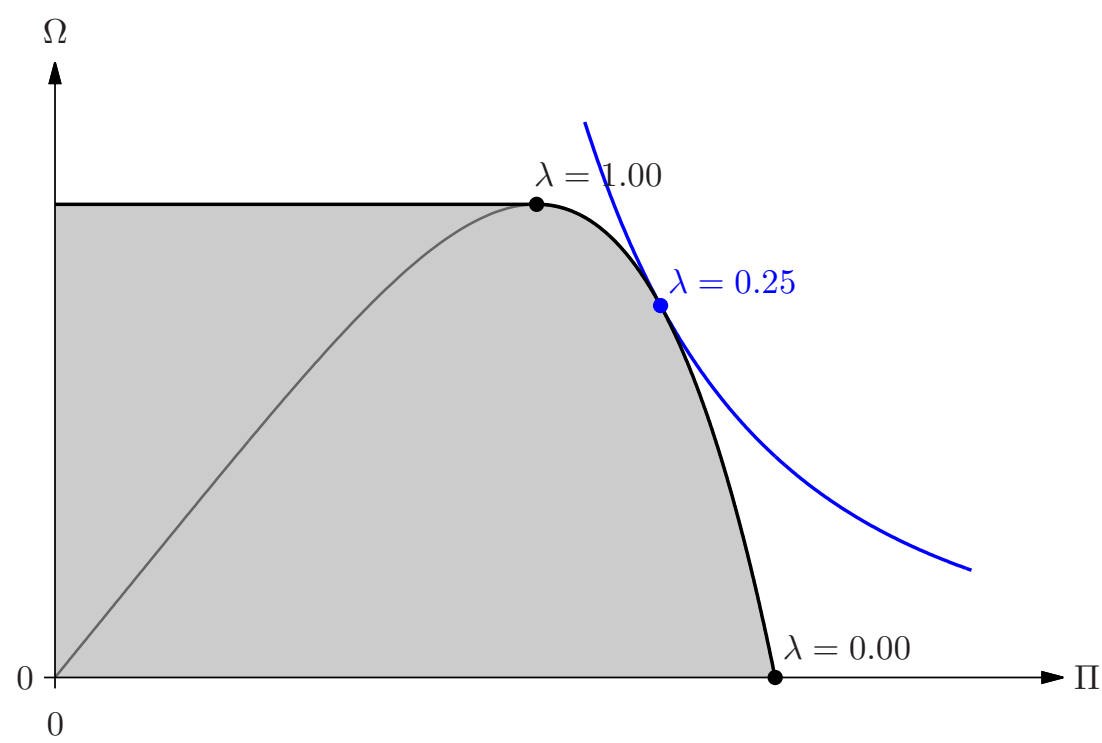

Figure 1: The set of feasible payoffs; blue: contour of the Nash product for $\lambda=0.25$ 
Proposition 3.1. There exists a unique solution to the bargaining problem (1). This solution is induced by a unique wage rate (or, equivalently, a unique employment level).

Proof. The existence of a unique bargaining solution follows from the convexity of the set of feasible payoffs (Lemma A.1) and from the strict convexity of the asymmetric Nash product. Because of the monotonicity of the profit function, there exists a unique wage rate or a unique employment level that induce this solution.

To simplify notation, let $\alpha:=w / p$ denote the real wage and define the "real" Nash product as

$$
\begin{aligned}
& \widetilde{N P}\left(\alpha, \theta^{e}, \lambda\right):=\left(n_{f} \Pi\left(1, \alpha, \frac{L}{n_{f}}\right)\right)^{1-\lambda}\left(\Omega\left(\theta^{e}, \alpha, L\right)\right)^{\lambda} \quad \text { subject to } \\
& \Omega\left(\theta^{e}, \alpha, L\right) \geq 0 \quad \text { and } \quad L=n_{f} h_{\mathrm{com}}(\alpha) .
\end{aligned}
$$

Because of

$$
\begin{aligned}
& \arg \max _{w \geq 0}\left\{N P\left(w, n_{f} h_{\text {com }}\left(\frac{w}{p}\right), \lambda\right)\right\}=\arg \max _{w \geq 0}\left\{\frac{1}{p} N P\left(w, n_{f} h_{\text {com }}\left(\frac{w}{p}\right), \lambda\right)\right\} \\
= & \arg \max _{w \geq 0}\left\{\widetilde{N P}\left(\frac{w}{p}, \frac{p^{e}}{p}, \lambda\right)\right\}=p \arg \max _{w / p \geq 0}\left\{\widetilde{N P}\left(\frac{w}{p}, \frac{p^{e}}{p}, \lambda\right)\right\},
\end{aligned}
$$

i. e., for given $\left(p^{e}, p\right) \gg 0$, the maximizer of the asymmetric Nash product in nominal terms (1) is $p$ times the maximizer of asymmetric Nash product in real terms (2), define

$$
W_{\mathrm{rtm}}: \mathbb{R}_{+} \times[0,1] \rightarrow \mathbb{R}_{+}, \quad W_{\mathrm{rtm}}\left(\theta^{e}, \lambda\right):=\arg \max _{\alpha \geq 0}\left\{\widetilde{N P}\left(\alpha, \theta^{e}, \lambda\right) \mid \Omega\left(\theta^{e}, \alpha, n_{f} h_{\mathrm{com}}(\alpha)\right) \geq 0\right\}
$$

which is the real wage that maximizes the asymmetric Nash product subject to a nonnegative level of the net wage bill $\Omega$ (note that the producers' right to manage always leads to individually rational solutions for producers due to the monotonicity of the profit function) and thus induces the bargaining solution.

In the boundary case of no union power $\lambda=0$ and for $\left(p^{e}, p\right) \gg 0$ given, the asymmetric Nash product is equal to aggregate profits, which are strictly monotonically decreasing in $\alpha$ and unbounded, implying that the constraint has to bind. Rewriting the condition $\Omega\left(\theta^{e}, \alpha, h_{\text {com }}(\alpha)\right)=0$ leads to $N\left(\alpha / \theta^{e}\right)=n_{f} h_{\text {com }}(\alpha)$, i. e. the real wage is chosen at the level at which the workers' maximal labor supply (their participation constraint or threshold level) and the profit-maximizing employment level are equalized.

For $\left(p^{e}, p\right) \gg 0$ and $0<\lambda \leq 1$ given, the objective function depends on the net wage bill so that the asymmetric Nash product attains positive values if and only if the constraint is not binding, i. e. in the case of an interior solution. Writing $L=n_{f} h_{\mathrm{com}}(\alpha)$, the first-order condition is

$$
\begin{aligned}
0 & \stackrel{!}{=} \frac{\partial \widetilde{N P}\left(\alpha, \theta^{e}, \lambda\right)}{\partial \alpha} \\
& =(\frac{\lambda}{\Omega\left(\theta^{e}, \alpha, L\right)} \frac{\mathrm{d} \Omega\left(\theta^{e}, \alpha, L\right)}{\mathrm{d} \alpha}+\frac{1-\lambda}{\Pi\left(1, \alpha, L / n_{f}\right)} \underbrace{\frac{\mathrm{d} \Pi\left(1, \alpha, L / n_{f}\right)}{\mathrm{d} \alpha}}_{=-L}) \widetilde{N P}\left(\alpha, \theta^{e}, \lambda\right),
\end{aligned}
$$




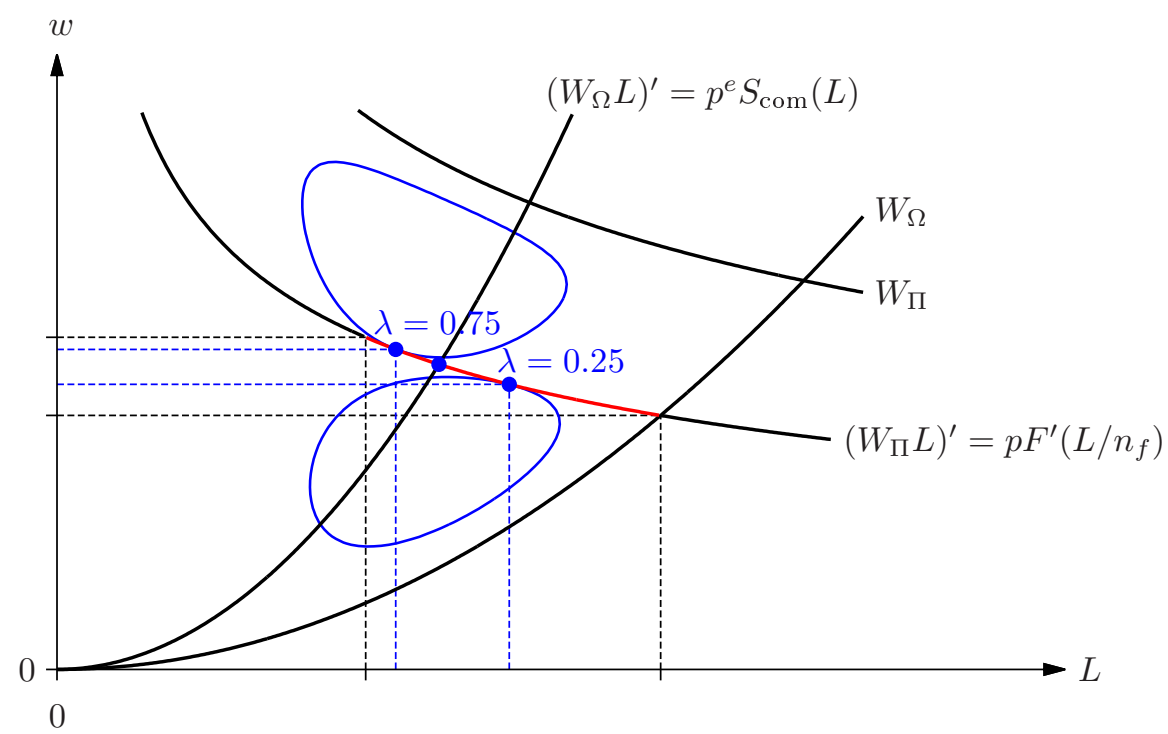

Figure 2: The bargaining solution given $p, p^{e}$; blue: contours of the Nash product for $\lambda=0.25$ resp. $\lambda=0.75$

It requires that, in absolute terms, normalized marginal union utility equals normalized aggregate profits, weighted by the relative power of the parties. Since the $\left(\Omega\left(\theta^{e}, \alpha, L\right) / \widetilde{N P}\left(\alpha, \theta^{e}, \lambda\right)\right)$ multiple of the right-hand side is linear in $\theta^{e}$ and $\lambda$, this condition can be explicitly solved for $\theta^{e}$ and $\lambda$, but only implicitly defines the real wage $\alpha$.

In order to formulate properties of the real wage $W_{\operatorname{rtm}}\left(\theta^{e}, \lambda\right)$, one assumption on the curvature of $\widetilde{N P}$ is stated.

Assumption 3.1. Let $\alpha$ be a local extremum of the asymmetric Nash product $\widetilde{N P}$ such that the second derivative of $\widetilde{N P}$ is bounded from above by

$$
\partial^{2} \widetilde{N P}\left(\alpha, \theta^{e}, \lambda\right) / \partial \alpha^{2}<-\left(\theta^{e} / \alpha\right) \partial^{2} \widetilde{N P}\left(\alpha, \theta^{e}, \lambda\right) / \partial \alpha \partial \theta^{e} .
$$

Lemma 3.1. The following statements hold true.

1. Under the assumptions on the production function $F(z)$ and the disutility of labor $v(\ell)$, the real wage $W_{r t m}\left(\theta^{e}, \lambda\right)$ is strictly monotonically increasing in both arguments.

2. If Assumption 3.1 holds, the elasticity of the real wage with respect to expected inflation is bounded by unity, i. e. $E_{W_{r t m}}\left(\theta^{e}\right)<1$.

Proof. See Appendix A.2.

Figure 2 provides a geometric characterization of the bargaining solution for two alternative levels of union power. Observe that for each $\lambda$, the Nash product defines a family of concentric contours in $(L, w)$ space with a unique global maximum. Due to the fact that the producer chooses a level of production where the real wage is equal to the marginal product, the bargaining solution for each $\lambda$ is given by a tangency condition of the marginal product curve and a level curve of the associated Nash product. 


\section{Underemployment and Overemployment}

Since both parties agree on the wage rate knowing that the resulting level of employment is equal to the corresponding competitive labor demand $n_{f} h_{\text {com }}(w / p)$, there cannot be involuntary unemployment. Any deviation of the employment level $n_{f} h_{\mathrm{com}}(w / p)$ from the desired supply $N_{\text {com }}\left(w / p^{e}\right)$ has to be a measure of voluntary underemployment. Therefore, define the underemployment rate as

$$
U\left(L, \frac{w}{p^{e}}\right):=\frac{N_{\mathrm{com}}\left(w / p^{e}\right)-L}{N_{\mathrm{com}}\left(w / p^{e}\right)}=1-\frac{L}{N_{\mathrm{com}}\left(w / p^{e}\right)} .
$$

It measures the gap between the actual employment and the aggregate amount which the workers would supply at the given wage level. Negative rates of underemployment are interpreted as voluntary overemployment or overtime. Thus, under right-to-manage bargaining, the underemployment rate coincides with the (percentage) Walrasian excess supply, i.e.

$$
U_{\mathrm{rtm}}\left(\frac{w}{p}, \frac{w}{p^{e}}\right):=1-\frac{n_{f} h_{\mathrm{com}}(w / p)}{N_{\mathrm{com}}\left(w / p^{e}\right)} .
$$

In Figure 2, the level of under- or overemployment can be read off directly as the horizontal distance of the bargainig solution on the marginal product curve to the competitive labor supply $N_{\text {com }}\left(w / p^{e}\right)$.

\section{Employment in Temporary Equilibrium}

After having derived the right-to-manage bargaining wage $p W_{\mathrm{rtm}}\left(p^{e} / p, \lambda\right)$ and the induced employment level $n_{f} h_{\mathrm{com}}\left(W_{\mathrm{rtm}}\left(p^{e} / p, \lambda\right)\right)$ as functions of prices, price expectations, and the bargaining parameter $\lambda$ in the previous section, it is straightforward to close the model in order to determine the properties of a temporary equilibrium under right-to-manage wage bargaining. The data at the beginning of an arbitrary period is aggregate money balances $M \geq 0$ held by old consumers, price expectations $p^{e}>0$, and the bargaining parameter $0 \leq \lambda \leq 1$.

\subsection{Aggregate Supply and Aggregate Demand}

Since every firm is a price taker on the competitive commodity market, aggregate commodity supply is that level of production induced by the bargaining agreement $W_{\mathrm{rtm}}\left(\theta^{e}, \lambda\right)$, i. e. it is defined by

$$
A S_{\mathrm{rtm}}\left(\theta^{e}, \lambda\right):=n_{f} F\left(h_{\mathrm{com}}\left(W_{\mathrm{rtm}}\left(\theta^{e}, \lambda\right)\right)\right)
$$

This function is strictly monotonically decreasing in both arguments

$$
\frac{\partial A S_{\mathrm{rtm}}\left(\theta^{e}, \lambda\right)}{\partial \theta^{e}}=n_{f} F^{\prime}\left(h_{\mathrm{com}}\left(W_{\mathrm{rtm}}\left(\theta^{e}, \lambda\right)\right)\right) h_{\mathrm{com}}^{\prime}\left(W_{\mathrm{rtm}}\left(\theta^{e}, \lambda\right)\right) \frac{\partial W_{\mathrm{rtm}}\left(\theta^{e}, \lambda\right)}{\partial \theta^{e}}<0
$$

resp.

$$
\frac{\partial A S_{\mathrm{rtm}}\left(\theta^{e}, \lambda\right)}{\partial \lambda}=n_{f} F^{\prime}\left(h_{\mathrm{com}}\left(W_{\mathrm{rtm}}\left(\theta^{e}, \lambda\right)\right)\right) h_{\mathrm{com}}^{\prime}\left(W_{\mathrm{rtm}}\left(\theta^{e}, \lambda\right)\right) \frac{\partial W_{\mathrm{rtm}}\left(\theta^{e}, \lambda\right)}{\partial \lambda}<0 .
$$


Since the wage paid by the producer under the right to manage always equals the marginal product of production, the share of total revenue allotted to the workers is

$$
\frac{w L}{p y}=\frac{F^{\prime}\left(L / n_{f}\right) L}{n_{f} F\left(L / n_{f}\right)}=E_{F}\left(\frac{L}{n_{f}}\right), \quad \text { with } L=n_{f} h_{\mathrm{com}}\left(W_{\mathrm{rtm}}\left(\theta^{e}, \lambda\right)\right)
$$

while

$$
\frac{\pi}{p y}=1-E_{F}\left(h_{\mathrm{com}}\left(W_{\mathrm{rtm}}\left(\theta^{e}, \lambda\right)\right)\right)
$$

is paid to the shareholders. Since only the latter group consumes when young, the incomeconsistent aggregate commodity demand must solve

$$
\begin{aligned}
y^{d} & =\frac{M}{p}+g+c\left(\theta^{e}\right)\left(1-\tau_{\pi}\right) \frac{\pi}{p y^{d}} \\
& =\frac{M}{p}+g+c\left(\theta^{e}\right)\left(1-\tau_{\pi}\right)\left(1-E_{F}\left(h_{\mathrm{com}}\left(W_{\mathrm{rtm}}\left(\theta^{e}, \lambda\right)\right)\right)\right) y^{d} .
\end{aligned}
$$

Therefore, the income-consistent aggregate demand function is given by

$$
D_{\mathrm{rtm}}\left(m, \theta^{e}, \lambda\right):=\frac{m+g}{1-c\left(\theta^{e}\right)\left(1-\tau_{\pi}\right)\left(1-E_{F}\left(h_{\mathrm{com}}\left(W_{\mathrm{rtm}}\left(\theta^{e}, \lambda\right)\right)\right)\right)},
$$

which is of the usual multiplier form with respect to real money balances $m:=M / p$ and government demand $g .{ }^{2}$ Compared to the situation with efficient bargaining, as discussed in Böhm \& Claas (2012), the union power parameter $\lambda$ enters only indirectly into the multiplier through the elasticity of production under the right to manage. Therefore, if $E_{F}$ is constant, there is neither an effect of union power $\lambda$ on the income distribution nor on aggregate demand. In other words, large union power induces a large deviation of employment from the associated competitive labor supply with almost no impact on aggregate income distribution while, under efficient bargaining, the union power is in a one-to-one correspondence of the relative income distribution between wages and profits.

While aggregate demand is obviously increasing in real money holdings $m$, i. e. $\partial D_{\mathrm{rtm}} / \partial m>0$, with an elasticity $E_{D_{\mathrm{rtm}}}(m)=m /(m+g)<1$ less than one, the effects of a change of expected inflation $\theta^{e}$ cannot be signed in general. If $\partial D_{\mathrm{rtm}} / \partial \theta^{e} \geq 0$ holds, aggregate demand is strictly monotonically decreasing in the commodity price $p$, i. e. $\mathrm{d} D_{\mathrm{rtm}} / \mathrm{d} p<0$. In the case of an isoelastic production function, the condition $\partial D_{\mathrm{rtm}} / \partial \theta^{e} \geq 0$ is equivalent to $c^{\prime} \leq 0$.

Definition 4.1. A temporary equilibrium is a pair $(p, w) \gg 0$ of prices and wages which simultaneously clears the commodity and the labor market. The levels at which both markets are cleared are the temporary equilibrium allocations $(y, L)=\left(n_{f} F\left(L / n_{f}\right), L\right) \gg 0$ of aggregate output and aggregate employment.

Since the labor market has been internalized in the aggregate supply function, the temporary equilibrium, given $\left(M, p^{e}, \lambda\right)$, is characterized by a price $p$ which clears the commodity market, i. e.

$$
D_{\mathrm{rtm}}\left(\frac{M}{p}, \frac{p^{e}}{p}, \lambda\right)=A S_{\mathrm{rtm}}\left(\frac{p^{e}}{p}, \lambda\right) .
$$

\footnotetext{
${ }^{2}$ If workers consume when young, a term depending on the net consumption propensity and on the elasticity of production has to be added to the multiplier.
} 


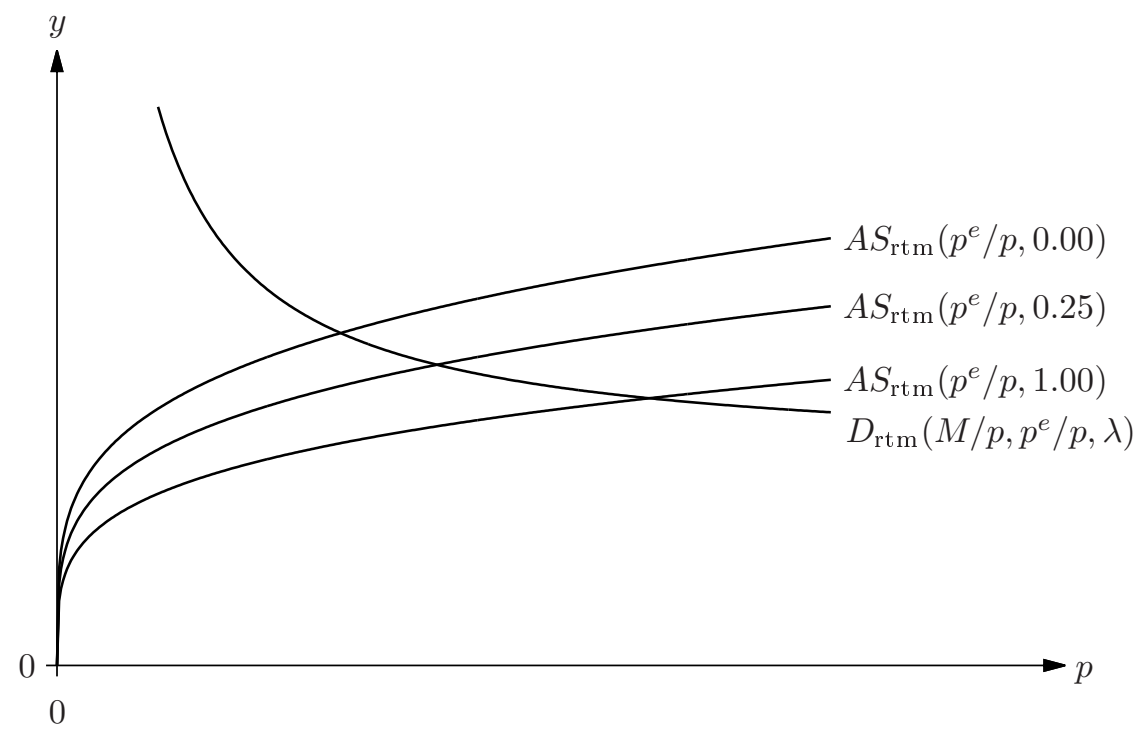

Figure 3: Temporary equilibrium for different levels of union power (with $\partial D_{\text {rtm }} / \partial \lambda=0$ )

Lemma 4.1. Let the aggregate supply function $A S_{r t m}$ be globally invertible and strictly monotonically decreasing with respect to expected inflation, and assume that $\partial D_{r t m} / \partial m>0$ and $\partial D_{r t m} / \partial \theta^{e} \geq 0$ hold. Then, for every $\left(M, p^{e}\right) \gg 0$ and $0 \leq \lambda \leq 1$, there exists a unique positive temporary equilibrium price $p>0$ solving (6).

Proposition 4.1. Under the assumptions of Lemma 4.1, there exists a differentiable mapping $\mathcal{P}_{\text {rtm }}: \mathbb{R}_{++}^{2} \times[0,1] \rightarrow \mathbb{R}_{++}$, called the price law, such that the unique positive equilibrium price is given by

$$
p=\mathcal{P}_{r t m}\left(M, p^{e}, \lambda\right) .
$$

The price law is homogeneous of degree one in $\left(M, p^{e}\right)$, for given $\lambda$.

\subsection{Properties of the Equilibrium Mappings}

In order to derive properties of the price law and the associated equilibrium mappings, assume for the remainder of this section that the aggregate demand function is nondecreasing in expected inflation and union power, i. e. $\partial D_{\mathrm{rtm}} / \partial \theta^{e} \geq 0$ and $\partial D_{\mathrm{rtm}} / \partial \lambda \geq 0$, and that Assumption 3.1 is fulfilled, i. e. the elasticity of the real wage function $W_{\mathrm{rtm}}$ is less than one.

\section{Properties of the Price Law}

Applying the Implicit Function Theorem to (6) with respect to $M$ yields

$$
\frac{\partial \mathcal{P}_{\mathrm{rtm}}}{\partial M}=-\frac{-\frac{1}{\mathcal{P}_{\mathrm{rtm}}} \frac{\partial D_{\mathrm{rtm}}}{\partial m}}{-\frac{\theta^{e}}{\mathcal{P}_{\mathrm{rtm}}} \frac{\partial A S_{\mathrm{rtm}}}{\partial \theta^{e}}+\frac{m}{\mathcal{P}_{\mathrm{rtm}}} \frac{\partial D_{\mathrm{rtm}}}{\partial m}+\frac{\theta^{e}}{\mathcal{P}_{\mathrm{rtm}}} \frac{\partial D_{\mathrm{rtm}}}{\partial \theta^{e}}}=\frac{\frac{\partial D_{\mathrm{rtm}}}{\partial m}}{-\theta^{e} \frac{\partial A S_{\mathrm{rtm}}}{\partial \theta^{e}}+m \frac{\partial D_{\mathrm{rtm}}}{\partial m}+\frac{\theta^{e}}{\mathcal{P}_{\mathrm{rtm}}} \frac{\partial D_{\mathrm{rtm}}}{\partial \theta^{e}}}>0
$$

and

$$
0<E_{\mathcal{P}_{\mathrm{rtm}}}(M)=\frac{\partial \mathcal{P}_{\mathrm{rtm}}}{\partial M} \frac{M}{\mathcal{P}_{\mathrm{rtm}}}=\frac{m \frac{\partial D_{\mathrm{rtm}}}{\partial m}}{-\theta^{e} \frac{\partial A S_{\mathrm{rtm}}}{\partial \theta^{e}}+m \frac{\partial D_{\mathrm{rtm}}}{\partial m}+\theta^{e} \frac{\partial D_{\mathrm{rtm}}}{\partial \theta^{e}}}<1,
$$


which shows that higher money balances induce higher prices with a positive elasticity less than one. Similar calculations yield

$$
\frac{\partial \mathcal{P}_{\mathrm{rtm}}}{\partial p^{e}}=-\frac{\frac{1}{\mathcal{P}_{\mathrm{rtm}}} \frac{\partial A S_{\mathrm{rtm}}}{\partial \theta^{e}}}{-\frac{\theta^{e}}{\mathcal{P}_{\mathrm{rtm}}} \frac{\partial A S_{\mathrm{rtm}}}{\partial \theta^{e}}+\frac{m}{\mathcal{P}_{\mathrm{rtm}}} \frac{\partial D_{\mathrm{rtm}}}{\partial m}+\frac{\theta^{e}}{\mathcal{P}_{\mathrm{rtm}}} \frac{\partial D_{\mathrm{rtm}}}{\partial \theta^{e}}}=\frac{-\frac{\partial A S_{\mathrm{rtm}}}{\partial \theta^{e}}}{-\theta^{e} \frac{\partial A S_{\mathrm{rtm}}}{\partial \theta^{e}}+m \frac{\partial D_{\mathrm{rtm}}}{\partial m}+\theta^{e} \frac{\partial D_{\mathrm{rtm}}}{\partial \theta^{e}}}>0
$$

and

$$
0<E_{\mathcal{P}_{\mathrm{rtm}}}\left(p^{e}\right)=\frac{\partial \mathcal{P}_{\mathrm{rtm}}}{\partial p^{e}} \frac{p^{e}}{\mathcal{P}_{\mathrm{rtm}}}=\frac{-\theta^{e} \frac{\partial A S_{\mathrm{rtm}}}{\partial e^{e}}}{-\theta^{e} \frac{\partial A S_{\mathrm{rtm}}}{\partial \theta^{e}}+m \frac{\partial D_{\mathrm{rtm}}}{\partial m}+\theta^{e} \frac{\partial D_{\mathrm{rtm}}}{\partial \theta^{e}}}<1
$$

which, as for money holdings, is less than unit-elastic.

\section{Output and Employment}

Given the price law $\mathcal{P}_{\operatorname{rtm}}\left(M, p^{e}, \lambda\right)$, the associated temporary equilibrium allocations are

$$
\begin{aligned}
y=\mathcal{Y}_{\mathrm{rtm}}\left(M, p^{e}, \lambda\right) & :=A S_{\mathrm{rtm}}\left(\frac{p^{e}}{\mathcal{P}_{\mathrm{rtm}}\left(M, p^{e}, \lambda\right)}, \lambda\right) \\
& \equiv D_{\mathrm{rtm}}\left(\frac{M}{\mathcal{P}_{\mathrm{rtm}}\left(M, p^{e}, \lambda\right)}, \frac{p^{e}}{\mathcal{P}_{\mathrm{rtm}}\left(M, p^{e}, \lambda\right)}, \lambda\right)
\end{aligned}
$$

which is the aggregate level of output traded at the temporary equilibrium price $\mathcal{P}_{\text {rtm }}\left(M, p^{e}, \lambda\right)$, and

$$
\begin{aligned}
L=\mathcal{L}_{\mathrm{rtm}}\left(M, p^{e}, \lambda\right) & :=n_{f} F^{-1}\left(\frac{1}{n_{f}} \mathcal{Y}_{\mathrm{rtm}}\left(M, p^{e}, \lambda\right)\right) \\
& =n_{f} h_{\mathrm{com}}\left(W_{\mathrm{rtm}}\left(\frac{p^{e}}{\mathcal{P}_{\mathrm{rtm}}\left(M, p^{e}, \lambda\right)}, \lambda\right)\right),
\end{aligned}
$$

which is the employment level it takes to produce $\mathcal{Y}_{\mathrm{rtm}}\left(M, p^{e}, \lambda\right)$. Due to the homogeneity of the price law, both mappings are homogenous of degree zero in $\left(M, p^{e}\right)$. Furthermore, they are strictly monotonically increasing (resp. decreasing) with respect to money holdings (resp. expectations).

$$
\begin{gathered}
0<E_{\mathcal{Y}_{\mathrm{rtm}}}(M)=-E_{A S_{\mathrm{rtm}}}\left(\theta^{e}\right) E_{\mathcal{P}_{\mathrm{rtm}}}(M)=\frac{-E_{A S_{\mathrm{rtm}}}\left(\theta^{e}\right) E_{D_{\mathrm{rtm}}}(m)}{-E_{A S_{\mathrm{rtm}}}\left(\theta^{e}\right)+E_{D_{\mathrm{rtm}}}(m)+E_{D_{\mathrm{rtm}}}\left(\theta^{e}\right)} \\
<\frac{-E_{A S_{\mathrm{rtm}}}\left(\theta^{e}\right)}{-E_{A S_{\mathrm{rtm}}}\left(\theta^{e}\right)+E_{D_{\mathrm{rtm}}}(m)+E_{D_{\mathrm{rtm}}}\left(\theta^{e}\right)}<1 \\
0<E_{\mathcal{L}_{\mathrm{rtm}}}(M)=E_{F^{-1}}\left(y / n_{f}\right) E_{\mathcal{Y}_{\mathrm{rtm}}}(M) \\
0>E_{\mathcal{Y}_{\mathrm{rtm}}}\left(p^{e}\right)=E_{A S_{\mathrm{rtm}}}\left(\theta^{e}\right)\left(1-E_{\mathcal{P}_{\mathrm{rtm}}}\left(p^{e}\right)\right)>E_{A S_{\mathrm{rtm}}}\left(\theta^{e}\right) \\
0>E_{\mathcal{L}_{\mathrm{rtm}}}\left(p^{e}\right)=E_{F^{-1}}\left(y / n_{f}\right) E_{\mathcal{Y}_{\mathrm{rtm}}}\left(p^{e}\right)
\end{gathered}
$$

Increasing levels of money holdings (resp. price expectations) induce higher (resp. lower) levels of output and employment. 


\section{Properties of the Wage Law}

Inserting the price law $\mathcal{P}_{\text {rtm }}$ into the wage function (3) yields the wage law

$$
w=\mathcal{W}_{\mathrm{rtm}}\left(M, p^{e}, \lambda\right):=\mathcal{P}_{\mathrm{rtm}}\left(M, p^{e}, \lambda\right) W_{\mathrm{rtm}}\left(\frac{p^{e}}{\mathcal{P}_{\mathrm{rtm}}\left(M, p^{e}, \lambda\right)}, \lambda\right),
$$

which shows that it encompasses the general-equilibrium price feedback from the commodity market. Due to the homogeneity of the price law, the wage law is also homogenous of degree one in $\left(M, p^{e}\right)$. Effects stemming from different levels of money holdings and price expectations on the wage rate can be calculated in the same fashion as before.

$$
\begin{aligned}
& E_{\mathcal{W}_{\mathrm{rtm}}}(M)=\underbrace{E_{\mathcal{P}_{\mathrm{rtm}}}(M)}_{\in(0,1)} \underbrace{\left(1-E_{W_{\mathrm{rtm}}}\left(\theta^{e}\right)\right)}_{\in(0,1)} \in\left(0, E_{\mathcal{P}_{\mathrm{rtm}}}(M)\right) \subset(0,1), \\
& E_{\mathcal{W}_{\mathrm{rtm}}}\left(p^{e}\right)=\underbrace{E_{\mathcal{P}_{\mathrm{rtm}}}\left(p^{e}\right)}_{\in(0,1)}+\underbrace{E_{W_{\mathrm{rtm}}}\left(\theta^{e}\right)}_{\in(0,1)} \underbrace{\left(1-E_{\mathcal{P}_{\mathrm{rtm}}}\left(p^{e}\right)\right)}_{\in(0,1)} \in\left(E_{\mathcal{P}_{\mathrm{rtm}}}\left(p^{e}\right), 1\right) \subset(0,1),
\end{aligned}
$$

i. e. nominal wages are increasing in money holdings and expectations while real wages are only increasing in price expectations, but decreasing in money holdings. Therefore, all effects of these two variables on the temporary equilibrium mappings have the same signs and are similar in size as in the related set-ups with competitve markets (Böhm 2010) or with efficient bargaining (Böhm \& Claas 2012).

\section{The Role of Union Power}

Applying the Implicit Function Theorem to (6) with respect to $\lambda$ yields

$$
\frac{\partial \mathcal{P}_{\mathrm{rtm}}}{\partial \lambda}=-\frac{\frac{\partial A S_{\mathrm{rtm}}}{\partial \lambda}-\frac{\partial D_{\mathrm{rtm}}}{\partial \lambda}}{-\frac{\theta^{e}}{\mathcal{P}_{\mathrm{rtm}}} \frac{\partial A S_{\mathrm{rtm}}}{\partial \theta^{e}}+\frac{m}{\mathcal{P}_{\mathrm{rtm}}} \frac{\partial D_{\mathrm{rtm}}}{\partial m}+\frac{\theta^{e}}{\mathcal{P}_{\mathrm{rtm}}} \frac{\partial D_{\mathrm{rtm}}}{\partial \theta^{e}}}>0,
$$

i. e. a higher level of union power results in a higher equilibrium price. This marks the major difference between the right-to-manage and the efficient-bargaining model where the price effect was strictly negative under the same assumptions for the consumption sector.

However, the effects of $\lambda$ on the equilibrium allocations cannot be signed, in general. Since the two elasticities on the allocation are given by

$$
\begin{aligned}
& E_{\mathcal{Y}_{\mathrm{rtm}}}(\lambda)=-\underbrace{\left(E_{D_{\mathrm{rtm}}}(m)+E_{D_{\mathrm{rtm}}}\left(\theta^{e}\right)\right)}_{>0} \underbrace{E_{\mathcal{P}_{\mathrm{rtm}}}(\lambda)}_{>0}+\underbrace{E_{D_{\mathrm{rtm}}}(\lambda)}_{\geq 0} \\
& E_{\mathcal{L}_{\mathrm{rtm}}}(\lambda)=\underbrace{E_{F^{-1}}\left(y / n_{f}\right)}_{>0} E_{\mathcal{Y}_{\mathrm{rtm}}(\lambda),}
\end{aligned}
$$

an increase in union power induces a mixed effect on output and employment. If the influence of union power on aggregate demand is small and can be neglected, output and employment levels are strictly monotonically decreasing in $\lambda$, as under efficient bargaining. Under an isoelastic production function, aggregate demand is independent of union power. This case has been depicted in the left panel of Figure 4. 

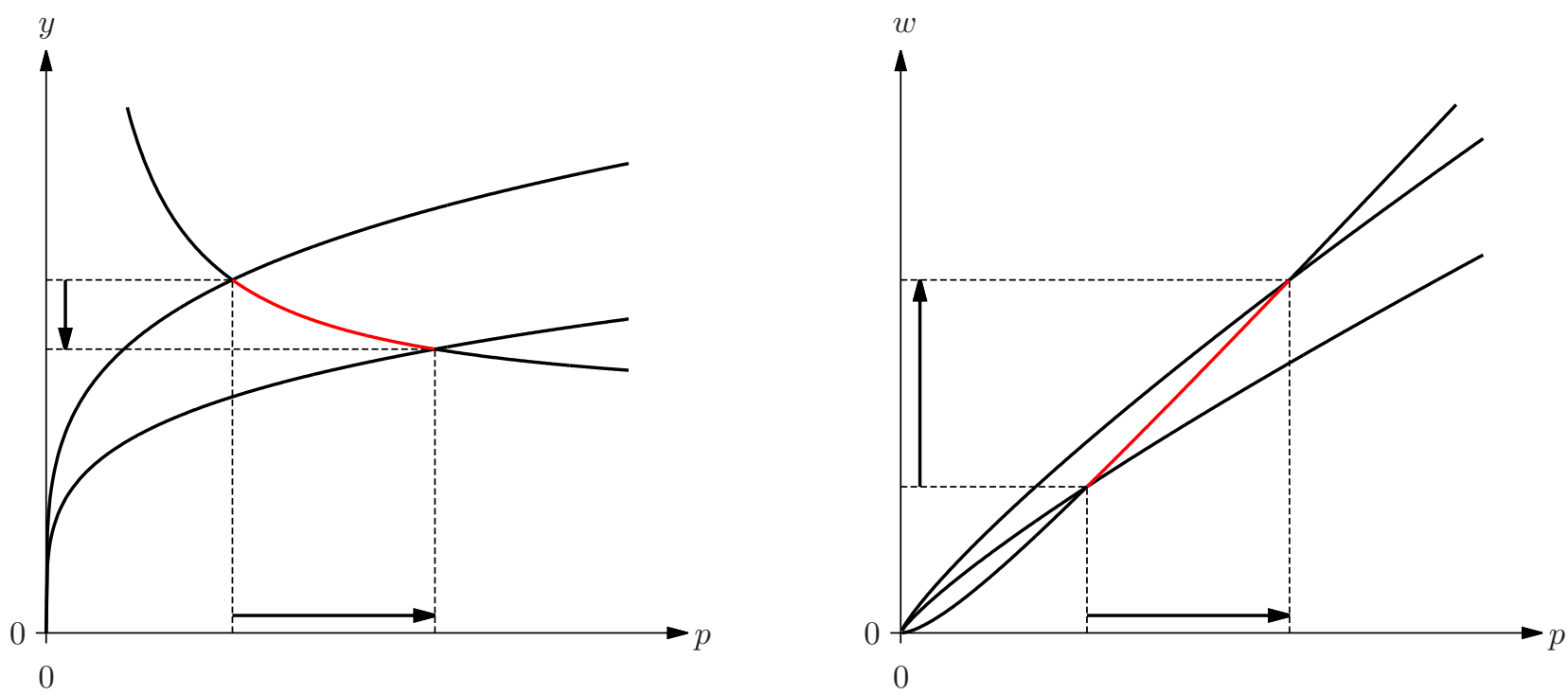

Figure 4: Range of prices, output, and wages for $\lambda \in[0,1]$ (with $\partial D_{\mathrm{rtm}} / \partial \lambda=0$ )

Finally, one obtains for the elasticity of the wage law with respect to $\lambda$

$$
E_{\mathcal{W}_{\mathrm{rtm}}}(\lambda)=\underbrace{E_{\mathcal{P}_{\mathrm{rtm}}}(\lambda)}_{>0} \underbrace{\left(1-E_{W_{\mathrm{rtm}}}\left(\theta^{e}\right)\right)}_{\in(0,1)}+\underbrace{E_{W_{\mathrm{rtm}}}(\lambda)}_{>0}>0
$$

which shows that the equilibrium wage rate is always increasing in $\lambda$. If $E_{D_{\mathrm{rtm}}}(\lambda)$ is sufficiently small, even the real wage is increasing in bargaining power.

$$
\begin{aligned}
E_{\mathcal{W}_{\mathrm{rtm}}}(\lambda)-E_{\mathcal{P}_{\mathrm{rtm}}}(\lambda) & =E_{W_{\mathrm{rtm}}}(\lambda)-E_{\mathcal{P}_{\mathrm{rtm}}}(\lambda) E_{W_{\mathrm{rtm}}}\left(\theta^{e}\right) \\
& =E_{W_{\mathrm{rtm}}}(\lambda)-\frac{-E_{A S_{\mathrm{rtm}}}(\lambda)+E_{D_{\mathrm{rtm}}}(\lambda)}{-E_{A S_{\mathrm{rtm}}}\left(\theta^{e}\right)+E_{D_{\mathrm{rtm}}}(m)+E_{D_{\mathrm{rtm}}}\left(\theta^{e}\right)} E_{W_{\mathrm{rtm}}}\left(\theta^{e}\right) \\
& =\frac{-1}{E_{F}(z) E_{h_{\mathrm{com}}}(\alpha)}\left(\frac{\left(-E_{A S_{\mathrm{rtm}}}(\lambda)+E_{D_{\mathrm{rtm}}}(\lambda)\right) E_{A S_{\mathrm{rtm}}}\left(\theta^{e}\right)}{-E_{A S_{\mathrm{rtm}}}\left(\theta^{e}\right)+E_{D_{\mathrm{rtm}}}(m)+E_{D_{\mathrm{rtm}}}\left(\theta^{e}\right)}-E_{A S_{\mathrm{rtm}}}(\lambda)\right) \\
& =\frac{-1}{E_{F}(z) E_{h_{\mathrm{com}}}(\alpha)} \frac{E_{A S_{\mathrm{rtm}}}\left(\theta^{e}\right) E_{D_{\mathrm{rtm}}}(\lambda)-E_{A S_{\mathrm{rtm}}}(\lambda)\left(E_{D_{\mathrm{rtm}}}(m)+E_{D_{\mathrm{rtm}}}\left(\theta^{e}\right)\right)}{-E_{A S_{\mathrm{rtm}}}\left(\theta^{e}\right)+E_{D_{\mathrm{rtm}}}(m)+E_{D_{\mathrm{rtm}}}\left(\theta^{e}\right)} \\
& \approx \frac{-1}{E_{F}(z) E_{h_{\mathrm{com}}}(\alpha)} \frac{-E_{A S_{\mathrm{rtm}}}(\lambda)\left(E_{D_{\mathrm{rtm}}}(m)+E_{D_{\mathrm{rtm}}}\left(\theta^{e}\right)\right)}{-E_{A S_{\mathrm{rtm}}}\left(\theta^{e}\right)+E_{D_{\mathrm{rtm}}}(m)+E_{D_{\mathrm{rtm}}}\left(\theta^{e}\right)}>0
\end{aligned}
$$

Since the equilibrium price and wage are determined simultaneously with (6), it is possible to derive an equivalent geometric representation in price-wage space to investigate the role of union power. The Inada conditions for the production function guarantee that the equilibrium condition (6) can be written equivalently as

$$
p F^{\prime}\left(n_{f} F^{-1}\left(\frac{D_{\mathrm{rtm}}\left(M / p, p^{e} / p, \lambda\right)}{n_{f}}\right)\right) \stackrel{!}{=} p F^{\prime}\left(n_{f} F^{-1}\left(\frac{A S_{\mathrm{rtm}}\left(p^{e} / p, \lambda\right)}{n_{f}}\right)\right),
$$

defining the equilibrium configuration in $(p, w)$ space. The graph of the left function depicts the demand-consistent wage while the graph of the right function defines the supplyconsistent wage under right-to-manage bargaining. Their intersection yields the equilibrium values $\left(\mathcal{P}_{\text {rtm }}\left(M, p^{e}, \lambda\right), \mathcal{W}_{\text {rtm }}\left(M, p^{e}, \lambda\right)\right)$, as shown in the right panel of Figure 4 and an increase 


\begin{tabular}{c|c|c|c|} 
& $M$ & $p^{e}$ & $\lambda$ \\
\hline $\mathcal{P}_{\text {rtm }}$ & + & + & + \\
\hline $\mathcal{W}_{\text {rtm }}$ & + & + & + \\
\hline $\mathcal{W}_{\text {rtm }} / \mathcal{P}_{\text {rtm }}$ & - & + & $(+)$ \\
\hline $\mathcal{Y}_{\text {rtm }}$ & + & - & $(-)$ \\
\hline $\mathcal{L}_{\text {rtm }}$ & + & - & $(-)$ \\
\hline
\end{tabular}

Table 1: Summary of comparative-statics analysis (for $\partial D_{\mathrm{rtm}} / \partial \lambda$ sufficiently small)

of $\lambda$ increases both the equilibrium price and wage. This contrasts with the case under efficient bargaining where the wage rate can be decreasing under some circumstances (see Böhm \& Claas 2012). Table 1 summarizes the results of the comparative-statics analysis.

It is informative to consider the global effect of the role of union power on wages and employment, respectively, on underemployment/overemployment. Figure 5 shows the range of

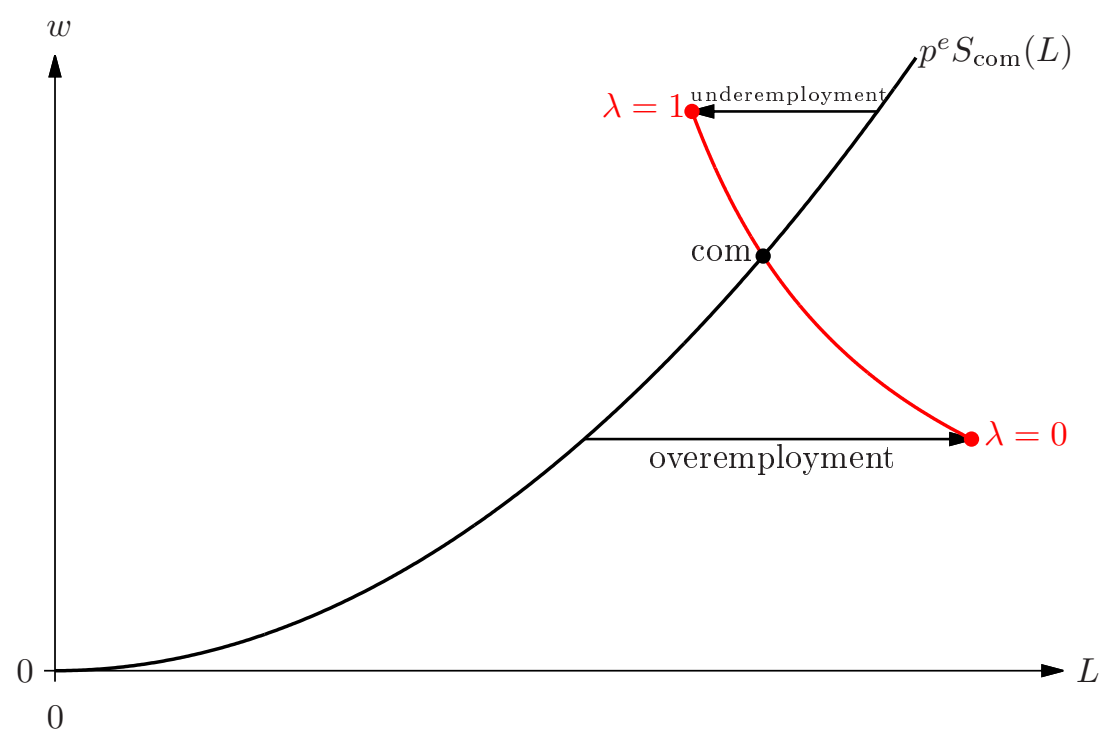

Figure 5: Range of employment and wages for $\lambda \in[0,1]$

bargaining equilibria as the union parameter changes from zero to one. This defines a curve in $(L, w)$ space for any pair $\left(M, p^{e}\right)$, which crosses the competitive labor supply function at a point where for the associated $\lambda$, the bargaining solution must coincide with the competitive solution. In other words, the competitive equilibrium of the economy is the outcome of the temporary equilibrium under right-to-manage bargaining for a particular value $\lambda_{\text {com of bar- }}$ gaining power. Since the effect of $\lambda$ on this curve is such that it crosses the competitive labor supply transversely, the level $\lambda_{\text {com }}$ is uniquely determined. Simultaneously, the diagram shows that this bargaining solution is the only temporary equilibrium under right to manage that has zero unemployment, in other words, for $\lambda>\lambda_{\text {com }}$, there is underemployment and for $\lambda<\lambda_{\text {com }}$, there is overemployment. 
Finally, the role of union power on equilibrium payoffs, i. e.

$$
\begin{aligned}
& \Pi_{\mathrm{rtm}}\left(M, p^{e}, \lambda\right):=\mathcal{P}_{\mathrm{rtm}}\left(M, p^{e}, \lambda\right) n_{f} F\left(\frac{\mathcal{L}_{\mathrm{rtm}}\left(M, p^{e}, \lambda\right)}{n_{f}}\right)-\mathcal{W}_{\mathrm{rtm}}\left(M, p^{e}, \lambda\right) \mathcal{L}_{\mathrm{rtm}}\left(M, p^{e}, \lambda\right), \\
& \boldsymbol{\Omega}_{\mathrm{rtm}}\left(M, p^{e}, \lambda\right):=\mathcal{W}_{\mathrm{rtm}}\left(M, p^{e}, \lambda\right) \mathcal{L}_{\mathrm{rtm}}\left(M, p^{e}, \lambda\right)-p^{e} S\left(\mathcal{L}_{\mathrm{rtm}}\left(M, p^{e}, \lambda\right)\right) \mathcal{L}_{\mathrm{rtm}}\left(M, p^{e}, \lambda\right),
\end{aligned}
$$

can be analyzed. However, it seems that no clear qualitative results can be established under the general set of assumptions because of multiple effects in opposite directions, unless more specific assumptions are made, as done in the following section.

\subsection{A Parametric Example: the Isoelastic Case}

In order to derive specific results on payoffs to discuss welfare issues, and to allow for a comparison with the model with efficient bargaining (Böhm \& Claas 2012), consider the model with a constant propensity to consume $0<c<1$ as well as with isoelastic production and labor supply functions. Let

$$
v(\ell)=\frac{C}{C+1} \ell^{1+\frac{1}{C}}, \quad 0<C<1,
$$

be the disutility from labor and let

$$
F(z)=\frac{A}{B} z^{B}, \quad A>0, \quad 0<B<1,
$$

be the production function. This implies that the reservation wage function and the inverse competitive labor supply are isoelastic functions of the form

$$
S(L)=\frac{C}{C+1} \frac{1}{1-\tau_{w}}\left(\frac{L}{n_{w}}\right)^{1 / C} \quad \text { and } \quad S_{\mathrm{com}}(L)=\frac{1}{1-\tau_{w}}\left(\frac{L}{n_{w}}\right)^{1 / C} .
$$

Solving the bargaining problem, one obtains an explicit form the real wage function (3) given by

$$
W_{\mathrm{rtm}}\left(\theta^{e}, \lambda\right)=A^{\frac{1}{C(1-B)+1}}\left(\frac{n_{f}}{n_{w}}\right)^{\frac{1-B}{C(1-B)+1}}\left(\frac{C}{C+1}\left(1+\lambda \frac{C(1-B)+1}{B C}\right) \frac{1}{1-\tau_{w}} \theta^{e}\right)^{\frac{C(1-B)}{C(1-B)+1}}
$$

which is itself an isoelastic function in expected inflation. Since the production function is isoelastic, the aggregate supply function is isoelastic as well.

The aggregate demand function (5) is given by

$$
D_{\mathrm{rtm}}(m)=\frac{m+g}{1-c\left(1-\tau_{\pi}\right)(1-B)},
$$

which is independent of expected inflation and bargaining power. ${ }^{3}$ Then, given $\left(M, p^{e}, \lambda\right)$, the temporary equilibrium price $p=\mathcal{P}_{\operatorname{rtm}}\left(M, p^{e}, \lambda\right)$ is implicitly defined by

$$
A S_{\mathrm{rtm}}\left(\frac{p^{e}}{p}, \lambda\right)=D_{\mathrm{rtm}}\left(\frac{M}{p}\right) \text {. }
$$

\footnotetext{
${ }^{3}$ First-period consumption of workers would result in an additional summand in the multiplier depending on their net propensity to consume.
} 


\begin{tabular}{c|c|c|c|} 
& $M$ & $p^{e}$ & $\lambda$ \\
\hline \hline $\mathcal{P}_{\text {rtm }}$ & + & + & + \\
\hline $\mathcal{W}_{\text {rtm }}$ & + & + & + \\
\hline $\mathcal{W}_{\text {rtm }} / \mathcal{P}_{\text {rtm }}$ & - & + & + \\
\hline $\mathcal{Y}_{\text {rtm }}, \mathcal{L}_{\text {rtm }}, \boldsymbol{\Pi}_{\text {rtm }} / \mathcal{P}_{\text {rtm }}$ & + & - & - \\
\hline $\mathcal{P}_{\text {rtm }} \mathcal{Y}_{\text {rtm }}, \boldsymbol{\Pi}_{\text {rtm }}, \mathcal{W}_{\text {rtm }} \mathcal{L}_{\text {rtm }}$ & + & + & + \\
\hline$\Omega_{\text {rtm }}$ & + & + & + \\
\hline$\Pi_{\text {rtm }}+\Omega_{\text {rtm }}$ & + & + & + \\
\hline
\end{tabular}

Table 2: Comparative-statics effects in the isoelastic example

In spite of the fact that the bargaining wage and employment level can be derived as explicit isoelastic functions for the partial equilibrium, it is impossible to obtain explicit algebraic expressions for the general-equilibrium values. This is due to the fact that structurally aggregate demand is not an isoelastic function whenever government demand is positive. Nevertheless, standard numerical procedures allow an explicit numerical and geometric analysis to portray correctly the properties of the respective general-equilibrium solutions. Furthermore, almost all comparative-statics effects can be calculated. They are derived in Section B.1 in the Appendix and their results are summarized in Table 2. The upper part of the table confirms the effects derived for the general case. Line 5 through line 7 indicate that all three state variables $\left(M, p^{e}, \lambda\right)$ show overall positive effects for the nominal variables of the bargaining problem, i.e. total income, total profits, and total wage income are monotonically increasing in money balances, expectations, and union power. Notice however that except for money balances, these come at the cost of lower output and lower employment. Therefore, in particular, an increase in union power increases wage income and profits, but it lowers employment.

The strong and universal monetary effects of union power under the right to manage contrasts with many of the findings of the literature, which are mainly derived under partial-equilibrium reasoning and at given prices. As shown, the general-equilibrium price feedback through the commodity market plays the decisive role in generating the nominal effects for the macroeconomy. Therefore, an evaluation of the impact of union power under the right to manage must recognize the positive price spillover between the labor market and the commodity market, which determines the size and direction of all comparative-statics effects in the economy from union power.

The isoelastic specifications not only allow to determine the effects of the state variables on the temporary equilibrium under right-to-manage wage bargaining, but also for a comparison with the related models with competition resp. efficient bargaining on the labor market. In order to distinguish between the different equilibrium mappings, the aggregate supply and demand functions, etc., which are associated with the different models, the subscripts "eff" (efficient bargaining), "com" (competition), and "rtm" (right to manage) are used in the following. Since

$$
D_{\mathrm{rtm}}\left(\frac{M}{p}\right) \equiv D_{\mathrm{com}}\left(\frac{M}{p}\right) \equiv D_{\mathrm{eff}}\left(\frac{M}{p}, \frac{B}{C(1-B)+1}\right)
$$

and

$$
A S_{\mathrm{rtm}}\left(\frac{p^{e}}{p}, \frac{B}{C(1-B)+1}\right) \equiv A S_{\mathrm{com}}\left(\frac{p^{e}}{p}\right) \equiv A S_{\mathrm{eff}}\left(\frac{p^{e}}{p}\right)
$$


the equilibrium conditions of all three models coincide at the level of bargaining power $\lambda=$ $B /(C(1-B)+1)$ for any given $\left(M, p^{e}\right)$. Furthermore, allocations, wages, and the rates of underemployment of the three models are the same at $\lambda=B /(C(1-B)+1)$. Therefore, $\lambda_{\text {com }}$, which has been implicitly defined as the level of bargaining power at which the rate of underemployment under the right to manage is zero, is explicitly given by

$$
\lambda_{\mathrm{com}}=\frac{B}{C(1-B)+1} .
$$

Since the competitive equilibrium coincides with the one of the right-to-manage model and of the efficient-bargaining model for the special case $\lambda=\lambda_{\text {com }}$, changes of money holdings and price expectations induce effects of the same sign in both models. Similar global comparative-statics effects can be established for the efficient-bargaining model for every value of $\lambda$.

\section{$5 \quad$ Union Power and the Macroeconomy}

While equilibrium allocations and wages under efficent bargaining resp. right-to-manage wage bargaining move in the same direction and only differ in magnitude if the union's bargaining power $\lambda$ changes, the equilibrium price moves in opposite directions. An increase of union power causes $\mathcal{P}_{\text {eff }}$ to decrease, but $\mathcal{P}_{\text {rtm }}$ to increase. This astonishing fact, visualized in Figure $6,{ }^{4}$ comes from the different channels through which $\lambda$ affects the temporary equilibrium. Since all

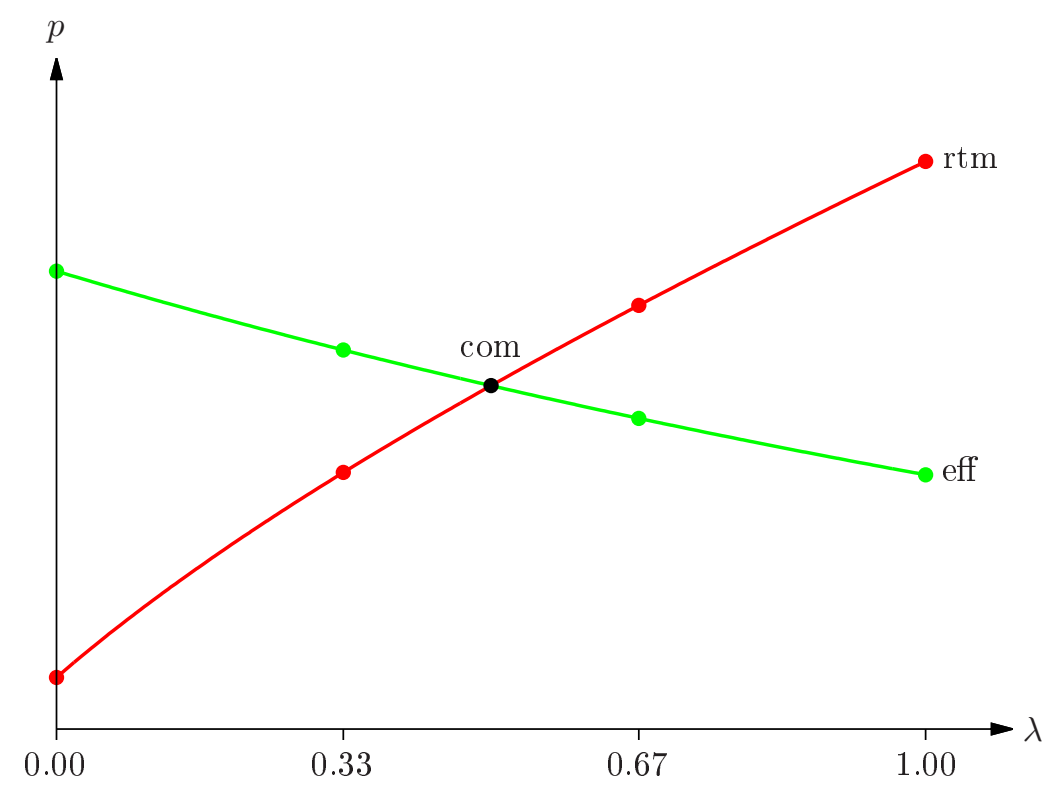

Figure 6: The role of union power on prices: right to manage (red), efficient bargaining (green)

three models coincide for $\lambda=\lambda_{\text {com }}$, the red (dark) and the green (light grey) curve in Figure 6 intersect at this level of union power with prices not being equal for any other value of $\lambda$.

To understand why equilibrium allocations under the two bargaining regimes are similarly affected by a change of bargaining power, consider the geometry displayed in Figure 7 . In the

\footnotetext{
${ }^{4}$ The results are summarized in geometric form to avoid long tedious calculations. All diagrams are drawn to scale for the values of the parameters given in Table 3 . Under this parameterization, $\lambda_{\text {com }}=0.5$.
} 


\begin{tabular}{|c|c|c|c|c|c|c|c|c|c|c|c|}
\hline$A$ & $B$ & $C$ & $\tau_{\pi}$ & $\tau_{w}$ & $n_{f}$ & $n_{w}$ & $c$ & $g$ & $M$ & $p^{e}$ & $\lambda$ \\
\hline 1 & 0.6 & 0.5 & 0.68 & 0.68 & 1 & 1 & 0.5 & 0.86 & 0.33 & 1 & 0.5 \\
\hline
\end{tabular}

Table 3: The parametrization used in the diagrams

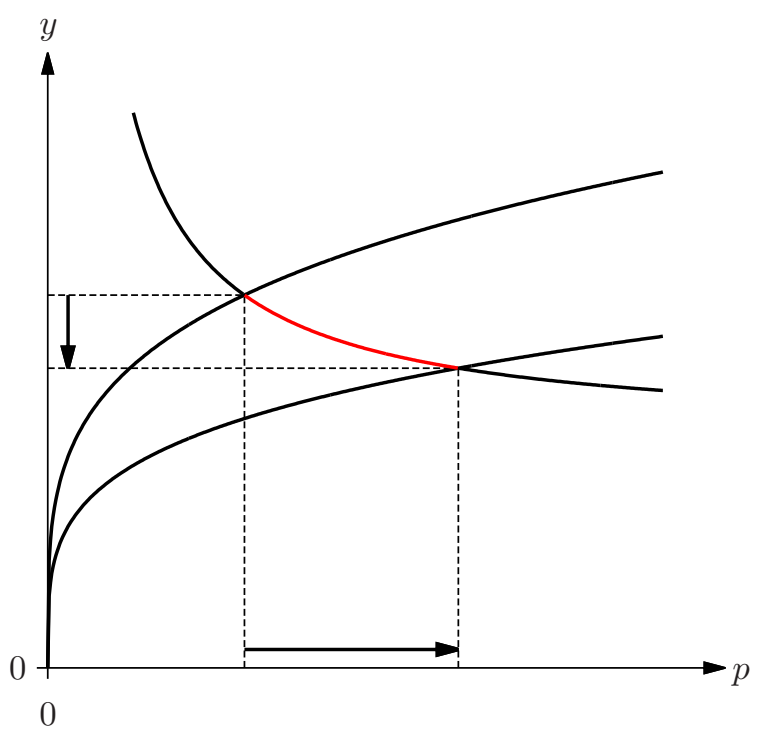

(a) right to manage

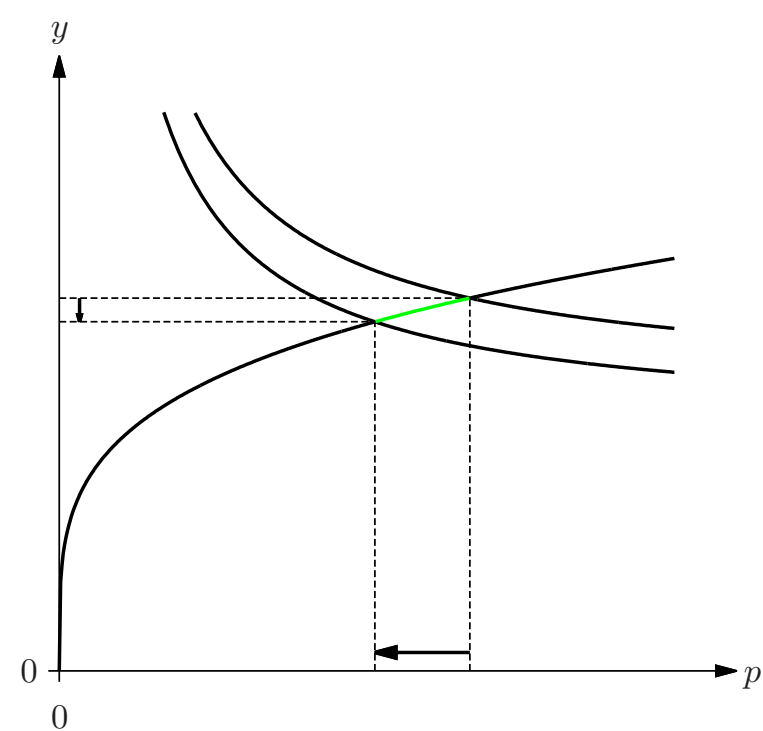

(b) efficient bargaining

Figure 7: Prices and output: right to manage vs. efficient bargaining; $\lambda \in[0,1]$

left panel, the aggregate supply function is negatively affected by $\lambda$ while aggregate demand remains unchanged. Therefore, an increase of union power results in a price increase while aggregate output (and thus employment) go down. In the right panel, commodity supply is independent of bargaining power while aggregate demand decreases in $\lambda$, which implies that both prices and output (and employment) decline in bargaining power, confirming that the same sign of the real impact, but an opposite one on prices.

Figure 8 shows the comparison of the equilibrium allocations in the space of aggregate employment and wages. As expected, the curve under right to manage (the bold red (dark) line) and under efficient bargaining (the green (light grey) line) intersect on the inverse competitive labor supply curve for $\lambda=\lambda_{\text {com. }}$. Since bargaining power negatively affects equilibrium aggregate employment and (usually) positively affects the equilibrium bargaining wage, both curves are decreasing in $(L, w)$ space. Under the chosen parametrization, the dispersion of employment levels is bigger under right to manage while the wage dispersion is bigger under efficient bargaining with the efficient bargaining curve lying closer to the labor supply curve. However, this observation heavily depends on the parametrization chosen and is reversed for high values of price expectations $p^{e}$. Surprisingly, the outcomes under the two regimes for any given level of $\lambda$ induce the same level of underemployment (visualized by the black isounderemployment curves). In order to show that the underemployment rates coincide, first note that

$$
W_{\mathrm{rtm}}\left(\theta^{e}, \lambda\right)=\left(\frac{C}{C+1}\left(1+\lambda \frac{C(1-B)+1}{B C}\right)\right)^{\frac{C(1-B)}{C(1-B)+1}} W_{\mathrm{rtm}}\left(\theta^{e}, \lambda_{\mathrm{com}}\right) .
$$




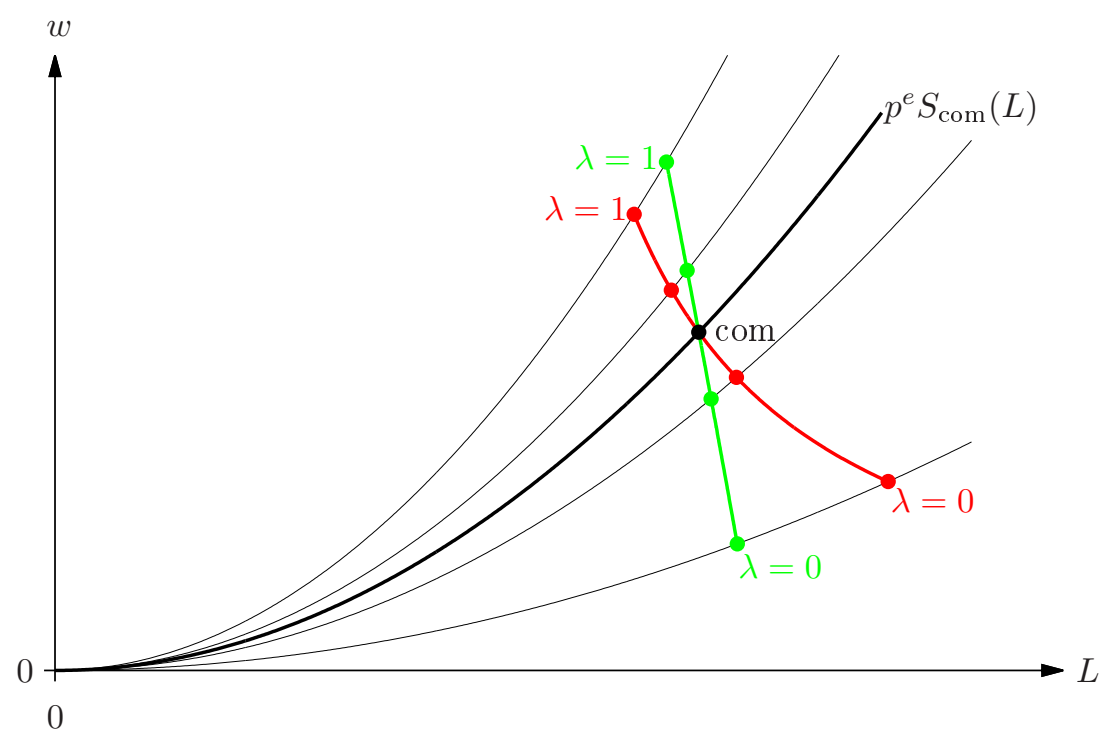

Figure 8: Employment and wages: right to manage vs. efficient bargaining; $\lambda \in[0,1]$

Then

$$
\begin{aligned}
N_{\text {com }}\left(\frac{W_{\mathrm{rtm}}\left(\theta^{e}, \lambda\right)}{\theta^{e}}\right) & =\left(\frac{C}{C+1}\left(1+\lambda \frac{C(1-B)+1}{B C}\right)\right)^{C \frac{C(1-B)}{C(1-B)+1}} \underbrace{N_{\mathrm{com}}\left(\frac{W_{\mathrm{rtm}}\left(\theta^{e}, \lambda_{\mathrm{com}}\right)}{\theta^{e}}\right)}_{=h_{\mathrm{com}}\left(W_{\mathrm{rtm}}\left(\theta^{e}, \lambda_{\mathrm{com}}\right)\right)} \\
& =\left(\frac{C}{C+1}\left(1+\lambda \frac{C(1-B)+1}{B C}\right)\right)^{\left(C+\frac{1}{1-B}\right) \frac{C(1-B)}{C(1-B)+1}} h_{\mathrm{com}}\left(W_{\mathrm{rtm}}\left(\theta^{e}, \lambda\right)\right) \\
& =\left(\frac{C}{C+1}\left(1+\lambda \frac{C(1-B)+1}{B C}\right)\right)^{C} h_{\mathrm{com}}\left(W_{\mathrm{rtm}}\left(\theta^{e}, \lambda\right)\right)
\end{aligned}
$$

implies that the rate of underemployment is independent of expected inflation

$$
\begin{aligned}
U_{\mathrm{rtm}}(.) & =1-\frac{h_{\mathrm{com}}\left(W_{\mathrm{rtm}}\left(\theta^{e}, \lambda\right)\right)}{N_{\mathrm{com}}\left(W_{\mathrm{rtm}}\left(\theta^{e}, \lambda\right) / \theta^{e}\right)} \\
& =1-\left(\frac{C}{C+1}\left(1+\lambda \frac{C(1-B)+1}{B C}\right)\right)^{-C}=U_{\mathrm{eff}}(.)
\end{aligned}
$$

and equal to the rate of underemployment under efficient bargaining, i. e. for a given $\lambda$, the employment-wage outcomes of the two models are located on the same isounderemployment curve. This result, however, strongly depends on the isoelastic structure.

Finally, the impact of the bargaining power $\lambda$ on equilibrium payoffs in the two scenarios also differs in a most surprising fashion, shown in Figure 9. Under efficient bargaining, there is a negative tradeoff between profits and the excess wage bill (in fact, $\Omega$ can even be decreasing for some parameterizations) with a maximal joint surplus for $\lambda=0$. In contrast, under the right to manage, both payoffs are increasing functions in the bargaining power. While this result seems counterintuitive at first sight, it can be explained recalling that profits always are a constant fraction of aggregate returns (i. e. of GNP). These are increasing in union power under the right to manage because of the positive effect of $\lambda$ on prices, which overcompensates the reduction of the production level. Furthermore, this rationale implies that real profits must decrease when $\lambda$ goes up. 


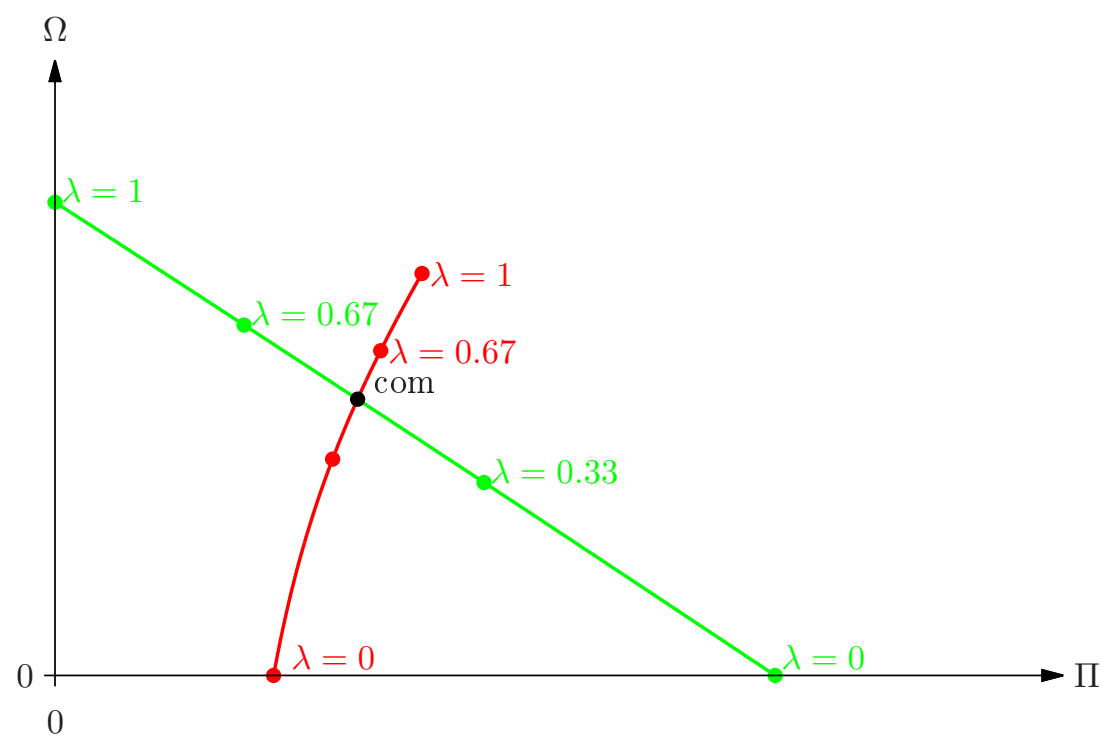

Figure 9: Profits and net wage bill: right to manage vs. efficient bargaining

Figure 10 provides an alternative explanation of this difference of the price feedback in the two cases. For $\lambda=\lambda_{\text {com }}$ the aggregate demand and aggregate supply functions are identical under the two bargaining regimes and under competition, leaving unclear how the objectives look like here. The point in which all equilibria coincide lies on a unique (and thus mutual) Nash product contour. Hence, the slopes of the two thin black perceived payoff curves and the blue Nash product contour must also be the same at this point, namely minus one. Due to the respective curvature properties, the perceived payoff under efficient bargaining, which is a line with slope minus one, must be a separating hyperplane between the perceived payoff curve under the right to manage and the Nash product level set.

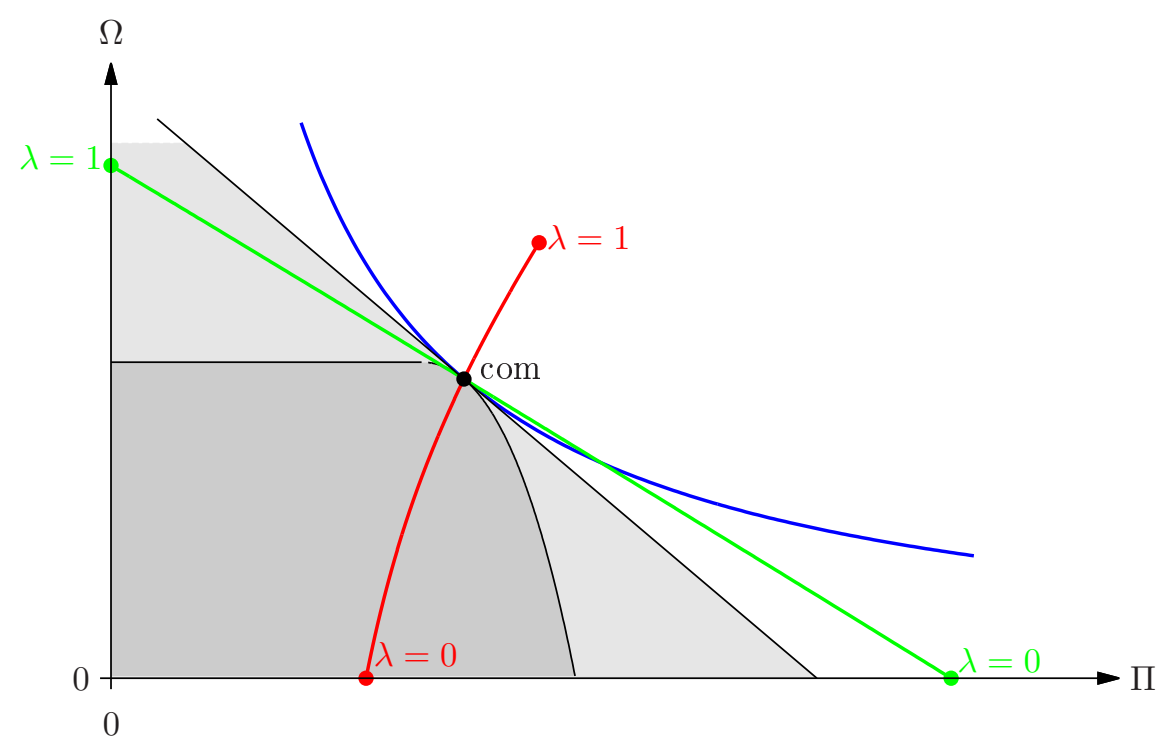

Figure 10: Comparing payoffs: right to manage vs. efficient bargaining

Due to the inverse relationship of aggregate payoff and bargaining power in the two scenarios, it is interesting to discover that there exist payoff-equivalent equilibria at different levels of 
union power in the two cases. Starting from $\lambda_{\text {eff }}=\lambda_{\text {com }}=\lambda_{\text {rtm }}$ for which the aggregate surplus coincides, continuity implies that there exist levels of bargaining power

$$
\lambda_{\text {eff }}<\lambda_{\text {com }}<\lambda_{\text {rtm }}
$$

such that the associated equilibrium payoffs yield the same (but higher) level of aggregate surplus at different supporting prices and different Nash product contours, as shown on Figure 11. A symmetric argument can be shown to hold for $\lambda_{\text {eff }}>\lambda_{\text {com }}>\lambda_{\text {rtm }}$ with an aggregate surplus

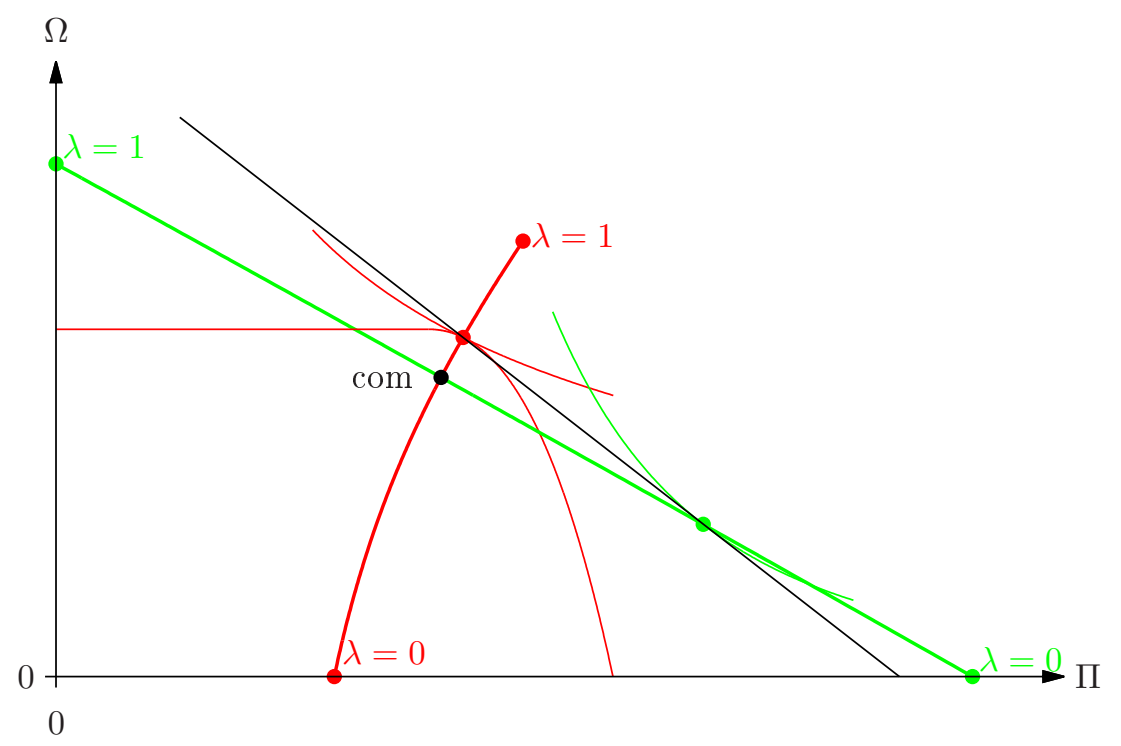

Figure 11: $\lambda_{\text {rtm }}>\lambda_{\text {eff }}$ induce the same aggregate payoff

below the one at the competitive level.

\section{Dynamics of Monetary Equilibrium under Perfect Foresight}

Given the fact that money balances and expectations are the two essential parameters determining a temporary equilibrium at each date in time $t$, a description of the dynamics of monetary equilibria of such economies requires a characterization of the dynamic evolution of money balances and expectation, assuming that the level of union power $\lambda$ remains constant over time. In this AS-AD economy with government activity but without monetary transfers, final (next period's initial) money holdings in each period are equal to aggregate savings, i. e.

$$
M_{t+1}:=\left(1-\tau_{w}\right) w_{t} L_{t}+\left(1-c\left(\theta_{t, t+1}^{e}\right)\right)\left(1-\tau_{\pi}\right) \pi_{t},
$$

where the temporary equilibrium prices, wages, allocations are given/determined by their respective equilibrium mappings as functions of $\left(M_{t}, p_{t, t+1}^{e}, \lambda\right)$. The income consistency $p_{t} y_{t}=$ $M_{t}+p_{t} g+c\left(\theta_{t, t+1}^{e}\right)\left(1-\tau_{\pi}\right) \pi_{t}$ implies that money balances can be rewritten as

$$
M_{t+1}=M_{t}+p_{t} g-\left(1-\left(1-\tau_{w}\right) \frac{w_{t} L_{t}}{p_{t} y_{t}}-\left(1-\tau_{\pi}\right) \frac{\pi_{t}}{p_{t} y_{t}}\right) p_{t} y_{t}
$$


showing that the change of money holdings from period $t$ to $t+1$ equals the deficit/surplus of the public budget where the term in parenthesis defines the average tax rate on aggregate income. Rewriting the tax rate and using the fact that under right-to-manage bargaining, the labor share of wages coincides with the elasticity of the production function, one obtains a function of $\left(M_{t}, p_{t, t+1}^{e}, \lambda\right)$

$$
\begin{aligned}
\tilde{\tau}\left(M_{t}, p_{t, t+1}^{e}, \lambda\right) & :=1-\left(1-\tau_{w}\right) E_{F}\left(L_{t} / n_{f}\right)-\left(1-\tau_{\pi}\right)\left(1-E_{F}\left(L_{t} / n_{f}\right)\right) \\
& =\left(\tau_{w}-\tau_{\pi}\right) E_{F}\left(L_{t} / n_{f}\right)+\tau_{\pi}
\end{aligned}
$$

whose values are always between 0 and $1 .^{5}$ Therefore, aggregate savings can be written as

$$
\begin{aligned}
M_{t+1} & =M_{t}+p_{t}\left(g-\tilde{\tau}\left(M_{t}, p_{t, t+1}^{e}, \lambda\right) y_{t}\right) \\
& =M_{t}+\mathcal{P}_{\mathrm{rtm}}\left(M_{t}, p_{t, t+1}^{e}, \lambda\right)\left(g-\tilde{\tau}\left(M_{t}, p_{t, t+1}^{e}, \lambda\right) \mathcal{Y}_{\mathrm{rtm}}\left(M_{t}, p_{t, t+1}^{e}, \lambda\right)\right) \\
& =: \mathcal{M}_{\mathrm{rtm}}\left(M_{t}, p_{t, t+1}^{e}, \lambda\right)
\end{aligned}
$$

defining the time-one map of money balances.

Concerning the evolution of expectations, only those will be considered which generate perfect foresight along orbits. A sequence of price expectations $\left\{p_{t, t+1}^{e}\right\}_{t=0}^{\infty}$ is said to satisfy the perfectforesight property if a forecast $p_{t-1, t}^{e}$ coincides with its associated realization $p_{t}$ for every $t$, i. e. if

$$
p_{t-1, t}^{e}=\mathcal{P}_{\mathrm{rtm}}\left(M_{t}, p_{t, t+1}^{e}, \lambda\right)
$$

holds for every $t$. To simplify the analysis for the remainder of this section, assume that aggregate demand is independent of expected inflation, i. e. $\partial D_{\mathrm{rtm}} / \partial \theta^{e}=0$, and that aggregate supply is globally invertible with respect to expected inflation. ${ }^{6}$ Then, solving (6) for the expected price yields an explicit forecasting rule, defined globally as

$$
p_{t, t+1}^{e}=\psi^{*}\left(M_{t}, p_{t-1, t}^{e}, \lambda\right) \equiv \mathcal{P}_{\mathrm{rtm}}^{e}\left(M_{t}, p_{t-1, t}^{e}, \lambda\right):=p_{t-1, t}^{e} A S_{\mathrm{rtm}}^{e}\left(D_{\mathrm{rtm}}\left(\frac{M_{t}}{p_{t-1, t}^{e}}\right), \lambda\right)
$$

where $A S_{\mathrm{rtm}}^{e}(y, \lambda)$ denotes the inverse of the aggregate supply function with respect to expected inflation. Then, the two mappings $\mathcal{M}_{\mathrm{rtm}}$ and $\psi^{*}$ define a two-dimensional dynamical system in money holdings and price expectations

$$
\left(\begin{array}{c}
M_{t+1} \\
p_{t+1, t+2}^{e}
\end{array}\right)=\left(\begin{array}{c}
\mathcal{M}_{\mathrm{rtm}}\left(M_{t}, p_{t, t+1}^{e}, \lambda\right) \\
\psi^{*}\left(\mathcal{M}_{\mathrm{rtm}}\left(M_{t}, p_{t, t+1}^{e}, \lambda\right), p_{t, t+1}^{e}, \lambda\right)
\end{array}\right) .
$$

Since along the orbits of this system, the perfect-foresight property hods, i.e. $p_{t-1, t}^{e}=p_{t}$ for all $t$, the dynamics can be written equivalently in terms of money and prices as

$$
\left(\begin{array}{c}
M_{t+1} \\
p_{t+1}
\end{array}\right)=\left(\begin{array}{c}
\mathcal{M}_{\mathrm{rtm}}\left(M_{t}, \psi^{*}\left(M_{t}, p_{t}, \lambda\right), \lambda\right) \\
\psi^{*}\left(M_{t}, p_{t}, \lambda\right)
\end{array}\right) .
$$

Thus, the existence of the globally defined perfect predictor guarantees well defined forewardrecursive equilibrium dynamics of prices and money balances under perfect foresight.

Since the system is homogeneous of degree one in money balances and prices, stationary states of this system fail to exist generically. In such cases, the appropriate stationary analysis considers so-called balanced orbits of monetary expansion along which real allocations of the economy are constant.

\footnotetext{
${ }^{5}$ If $F(z)$ is isoelastic with elasticity $0<B<1, \tilde{\tau}\left(M_{t}, p_{t, t+1}^{e}, \lambda\right) \equiv\left(\tau_{w}-\tau_{\pi}\right) B+\tau_{\pi}$ is constant.

${ }^{6}$ This allows for the more efficient notation $D_{\mathrm{rtm}}\left(m_{t}\right)$ which is used instead of $D_{\mathrm{rtm}}\left(m_{t}, \theta_{t, t+1}^{e}, \lambda\right)$.
} 
Definition 6.1. An orbit $\left\{\left(M_{t}, p_{t}\right)\right\}_{t=0}^{\infty}$ of $(7)$ is called a balanced path if there exists an $m>0$ such that $m_{t}:=M_{t} / p_{t}=m$ for every $t$.

Exploiting the homogeneity of the two mappings of (7) describing the dynamics of nominal money balances and prices yields a time-one map for real balances given by

$$
\begin{aligned}
m_{t+1}= & \frac{M_{t+1}}{p_{t+1}}=\frac{\mathcal{M}_{\mathrm{rtm}}\left(M_{t}, \psi^{*}\left(M_{t}, p_{t}, \lambda\right), \lambda\right)}{\psi^{*}\left(M_{t}, p_{t}, \lambda\right)} \\
= & \frac{p_{t}\left(\frac{M_{t}}{p_{t}}+g-\tilde{\tau}_{\psi^{*}}\left(A S_{\mathrm{rtm}}^{e}\left(D_{\mathrm{rtm}}\left(\frac{M_{t}}{p_{t}}\right), \lambda\right)\right) D_{\mathrm{rtm}}\left(\frac{M_{t}}{p_{t}}\right)\right)}{p_{t} A S_{\mathrm{rtm}}^{e}\left(D_{\mathrm{rtm}}\left(\frac{M_{t}}{p_{t}}\right), \lambda\right)} \\
= & \frac{m_{t}+g-\tilde{\tau}_{\psi^{*}}\left(A S_{\mathrm{rtm}}^{e}\left(D_{\mathrm{rtm}}\left(m_{t}\right), \lambda\right)\right) D_{\mathrm{rtm}}\left(m_{t}\right)}{A S_{\mathrm{rtm}}^{e}\left(D_{\mathrm{rtm}}\left(m_{t}\right), \lambda\right)}=: \mathcal{F}\left(m_{t}\right)
\end{aligned}
$$

where

$$
\tilde{\tau}_{\psi^{*}}\left(\theta^{e}\right):=\left(\tau_{w}-\tau_{\pi}\right) E_{F}\left(h_{\mathrm{com}}\left(W_{\mathrm{rtm}}\left(\theta^{e}, \lambda\right)\right)\right)+\tau_{\pi}
$$

defines the average tax rate under perfect foresight with

$$
\tilde{\tau}\left(M_{t}, p_{t, t+1}^{e}, \lambda\right) \equiv \tilde{\tau}_{\psi^{*}}\left(\frac{p_{t, t+1}^{e}}{\mathcal{P}_{\mathrm{rtm}}\left(M_{t}, p_{t, t+1}^{e}, \lambda\right)}\right) .
$$

Because of the linearity of aggregate demand in $m_{t}+g$, the system (8) can be written as

$$
m_{t+1}=\left(\tilde{c}-\tilde{\tau}_{\psi^{*}}\left(A S_{\mathrm{rtm}}^{e}\left(D_{\mathrm{rtm}}\left(m_{t}\right), \lambda\right)\right)\right) \frac{D_{\mathrm{rtm}}\left(m_{t}\right)}{A S_{\mathrm{rtm}}^{e}\left(D_{\mathrm{rtm}}\left(m_{t}\right), \lambda\right)} .
$$

Whenever the effects stemming from the average tax rate $\tilde{\tau}_{\psi^{*}}$ can be neglected (e.g. in the isoelastic case), the strict monotonicity of $A S_{\mathrm{rtm}}^{e}$ implies that $\mathcal{F}\left(m_{t}\right)$ is strictly monotonically increasing and strictly convex in $m_{t}$. Since an increase of public consumption $g$ constitutes a left shift of the time-one map, there exists a unique level $g^{\star}(\lambda)$ of public consumption such that exactly two positive fixed points exist if and only if $0<g<g^{\star}(\lambda)$. In this case, which is depicted in Figure 12, the lower fixed point is asymptotically stable and the upper fixed point is unstable. ${ }^{7}$ To exhibit the typical dynamical features, it is informative to consider the isoelastic case treated in the previous section. One obtains the system

$$
m_{t+1}=\frac{\tilde{c}-\tilde{\tau}}{A S_{\mathrm{rtm}}^{e}(1, \lambda)} D_{\mathrm{rtm}}\left(m_{t}\right)^{1+\frac{C(1-B)+1}{B C}}=\frac{\tilde{c}-\tilde{\tau}}{A S_{\mathrm{rtm}}^{e}(1, \lambda)} D_{\mathrm{rtm}}\left(m_{t}\right)^{\frac{C+1}{B C}},
$$

which is isoelastic in $D_{\mathrm{rtm}}\left(m_{t}\right)$ with elasticity $\frac{C+1}{B C}>1$. The root of the dynamical system (9) evaluated at a positive fixed point $m$ is

$$
E_{\mathcal{F}}(m)=E_{D_{\mathrm{rtm}}}(m) \frac{C+1}{B C}=\frac{m}{m+g} \frac{C+1}{B C} .
$$

For two-dimensional homogeneous systems, it is known that the stability of the one-dimensional system (9) is only a necessary condition for asymptotic stability of balanced paths. Their analysis requires a separate two-dimensional investigation of stability. ${ }^{8}$

\footnotetext{
${ }^{7}$ These results correspond to the ones of the models with competition (Böhm 2010) and efficient bargaining (Böhm \& Claas 2012).

${ }^{8}$ see Deardorff (1970); Böhm, Pampel \& Wenzelburger (2005); Pampel (2009)
} 

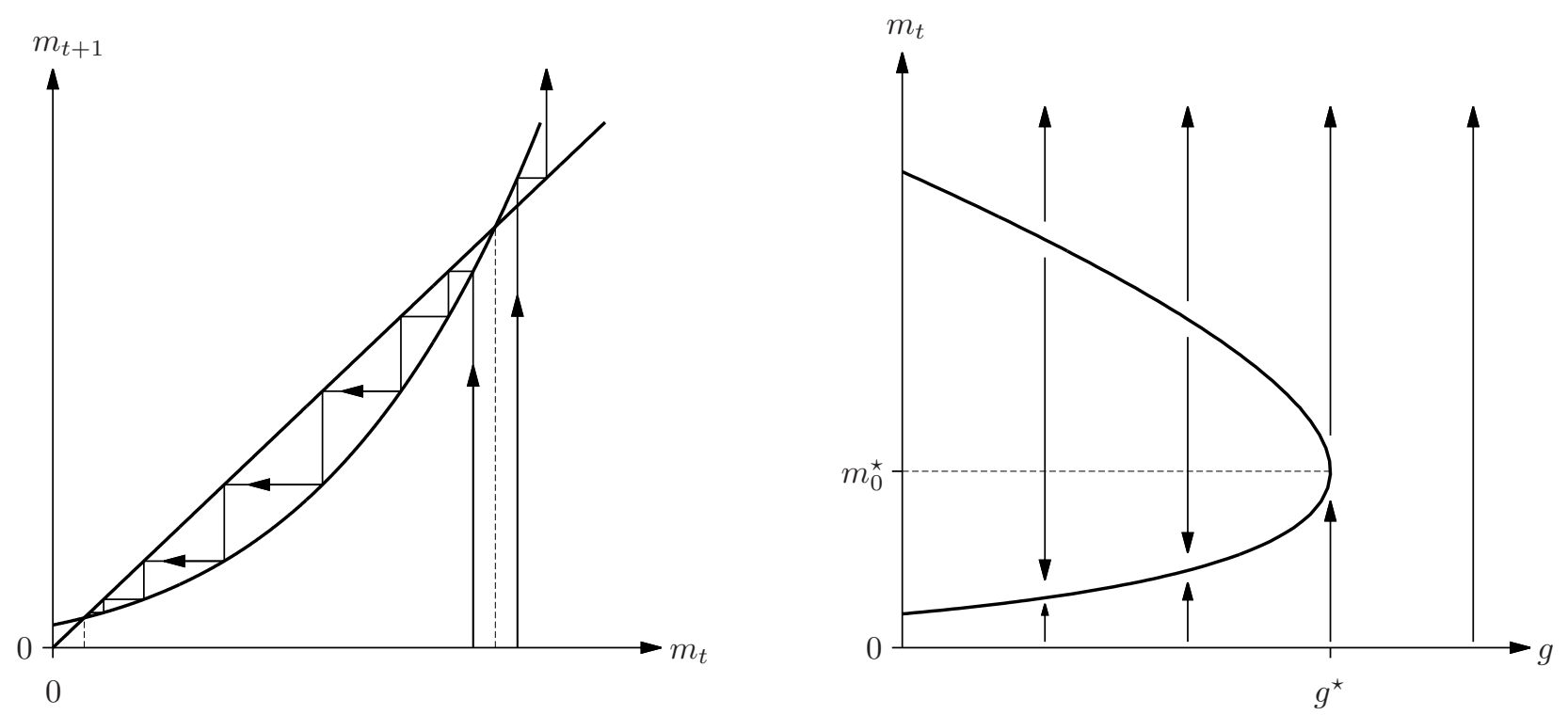

Figure 12: Stability and convergence

Definition 6.2. Let $\left\{\left(M_{t}, p_{t}\right)\right\}_{t=0}^{\infty}$ be an orbit of the system (7) and let $m$ be a fixed point of the associated one-dimensional system (8). The orbit is said to converge to a balanced path associated with $m$ if $m_{t}=M_{t} / p_{t}$ converges to $m$ and

$$
\Delta_{t}:=M_{t}-m p_{t}=\left(m_{t}-m\right) p_{t}
$$

converges to zero for $t \rightarrow \infty$.

The number $\Delta_{t}$ measures the (vertical) distance between the orbit and the set of balanced paths. One can write

$$
\begin{aligned}
\Delta_{t+1} & =\left(m_{t+1}-m\right) p_{t+1}=\frac{m_{t+1}-m}{m_{t}-m} \frac{p_{t+1}}{p_{t}} \Delta_{t} \\
& =\frac{m_{t+1}-m}{m_{t}-m} A S_{\mathrm{rtm}}^{e}\left(D_{\mathrm{rtm}}\left(m_{t}\right), \lambda\right) \Delta_{t}
\end{aligned}
$$

which shows that $\Delta_{t+1}$ is linear in $\Delta_{t}$ and which gives the two-dimensional system in $\left(m_{t}, \Delta_{t}\right)$

$$
\left(\begin{array}{c}
m_{t+1} \\
\Delta_{t+1}
\end{array}\right)=\left(\begin{array}{c}
\mathcal{F}\left(m_{t}\right) \\
\frac{\mathcal{F}\left(m_{t}\right)-m}{m_{t}-m} A S_{\mathrm{rtm}}^{e}\left(D_{\mathrm{rtm}}\left(m_{t}\right), \lambda\right) \Delta_{t}
\end{array}\right)
$$

Due to the skewness of $(10)$, a fixed point $(m, 0)$ is asymptotically stable if and only if

$$
\frac{\partial m_{t+1}}{\partial m_{t}}=\mathcal{F}^{\prime}(m) \quad \text { and } \quad \frac{\partial \Delta_{t+1}}{\partial \Delta_{t}}=\mathcal{F}^{\prime}(m) A S_{\mathrm{rtm}}^{e}\left(D_{\mathrm{rtm}}(m), \lambda\right)=\frac{\tilde{c}-\tilde{\tau}}{\tilde{c}} \frac{C+1}{B C}
$$

are less than one in absolute value. Both roots are positive. The second one equals the first $\partial m_{t+1} / \partial m_{t}$ multiplied by the expected rate of inflation along the balanced path $m$. The algebraic expression shows for the isoelastic case that it is independent of the fixed point $m$ of $\mathcal{F}$ and of union power $\lambda$. Therefore, the balanced path is asymptotically stable if $m$ is an asymptotically stable fixed point of $\mathcal{F}$, i. e. $\mathcal{F}^{\prime}(m)=E_{\mathcal{F}}(m)<1$, and if the expected rate of inflation is not "too large" so that the product $\mathcal{F}^{\prime}(m) A S_{\text {rtm }}^{e}\left(D_{\mathrm{rtm}}(m), \lambda\right)$ is still less than one. In other words, asymptotic stability of $(m, 0)$ requires that the expected rate of inflation along the balanced path is bounded by $1 / \mathcal{F}^{\prime}(m)$. Geometrically speaking, this means that the force that pulls an orbit to the set of balanced paths associated with $m$ dominates the inflationary force driving the system away from the path. 


\section{Summary and Conclusion}

This paper provides a complete integration of the right-to-manage wage bargaining approach into a variant of the aggregate supply-aggregate demand model in full generality. It is shown that temporary equilibria under the right to manage exist under the same set of assumptions as in the case of a competitive labor market or under efficient bargaining (as in Böhm 2010; Böhm \& Claas 2012). Since the level of union power is a free parameter to be chosen between 0 and 1, the results describe economic scenarios of a wide range of possible noncompetitive situations of distribution of the bargaining power between unions and syndicates. Most importantly, a full general-equilibrium integration of the right-to-manage approach into a consistent monetary macroeconomic model with a competitive output market is obtained, characterizing completely the intermarket feedback structure. Thus, all macroeconomic effects of the rightto-manage approach, as opposed to most of the partial-equilibrium analysis of the literature, are analyzed.

As a consequence of this integration of the feedback structure, the comparative-statics properties for the macroeconomy are derived for the essential state variables: money balances, expectations, and union power. While these properties with respect to money balances and expectations are qualitatively similar to the competitive as well as to the efficient-bargaining model, the paper derives a strong positive impact of union power on the temporary price. This difference arises from the fact that the temporary equilibrium price is affected through aggregate supply instead of aggregate demand under efficient bargaining, which contrasts strongly with a negative price impact under efficient bargaining.

Due to the opposite price effect, both aggregate (nominal) profits and the excess wage sum increase in bargaining power. From this view point, the bargaining agents would hence prefer a strong (precisely: a monopolistic) union to maximize both nominal payoffs. These gains, however, come at the cost of lower output and less employment, and because of the higher commodity price, result in less consumption of old consumers and of higher governmental spendings.

Several extensions and modifications of this model seem to be promising. Symmetric to the right-to-manage wage bargaining discussed so far, a right-to-work wage bargaining scenario can be considered, in which the union determines the level of employment after a wage rate has been negotiated. In this case, the desired (notional) level of employment could be guaranteed to all workers, implying a rate of underemployment equal to zero. However, this would induce a demand side measure of factor usage of the producer defined by the difference of the level of employment and the associated notional labor demand at the actual real wage.

In the above analysis, the level of bargaining power is assumed to be constant and exogenously given. This implies dynamical features, which are structurally the same as in the competitive and the efficient-bargaining settings. It remains an open question to what extent an intertemporal adjustment of bargaining power would lead to interesting and qualitatively different effects for the long-run behavior of the economy. 


\section{A Proofs}

\section{A.1 Convexity of the Set of Feasible Payoffs}

Lemma A.1. The set of feasible points of the bargaining problem (1) is convex.

Proof. It suffices to show that the payoff frontier is concave in the payoff space. To this end, let $\left(p^{e}, p\right) \gg 0$ be given, let $0<\beta<1$, and for $i=1$, 2 let

$$
\left(n_{f} \Pi\left(p, p F^{\prime}\left(\frac{L_{i}}{n_{f}}\right), \frac{L_{i}}{n_{f}}\right), \Omega\left(p^{e}, p F^{\prime}\left(\frac{L_{i}}{n_{f}}\right), L_{i}\right)\right)
$$

be two points on the payoff frontier, w. l.o.g. $L_{1}<L_{2}$. Due to the strict monotonicity of the perceived profits, there exists a unique $L_{3} \in\left(L_{1}, L_{2}\right)$ such that

$$
\Pi\left(p, p F^{\prime}\left(\frac{L_{3}}{n_{f}}\right), \frac{L_{3}}{n_{f}}\right)=\beta \Pi_{1}+(1-\beta) \Pi_{2} .
$$

Note that $n_{f} p F\left(L / n_{f}\right)-p^{e} S(L) L$ is strictly concave in $L$ because $F(z)$ is strictly concave in $z$ and $S(L) L$ is convex in $L$. Then, the following equations/inequalities

$$
\begin{aligned}
& \Omega\left(p^{e}, p F^{\prime}\left(\frac{L_{3}}{n_{f}}\right), L_{3}\right)=p F^{\prime}\left(\frac{L_{3}}{n_{f}}\right) L_{3}-p^{e} S\left(L_{3}\right) L_{3} \\
&= n_{f} p F\left(\frac{L_{3}}{n_{f}}\right)-n_{f} \Pi\left(p, p F^{\prime}\left(\frac{L_{3}}{n_{f}}\right), \frac{L_{3}}{n_{f}}\right)-p^{e} S\left(L_{3}\right) L_{3} \\
&> \beta\left(n_{f} p F\left(\frac{L_{1}}{n_{f}}\right)-p^{e} S\left(L_{1}\right) L_{1}\right)+(1-\beta)\left(n_{f} p F\left(\frac{L_{2}}{n_{f}}\right)-p^{e} S\left(L_{2}\right) L_{2}\right)- \\
& \quad n_{f} \Pi\left(p, p F^{\prime}\left(\frac{L_{3}}{n_{f}}\right), \frac{L_{3}}{n_{f}}\right) \\
&= \beta\left(n_{f} p F\left(\frac{L_{1}}{n_{f}}\right)-p^{e} S\left(L_{1}\right) L_{1}\right)+(1-\beta)\left(n_{f} p F\left(\frac{L_{2}}{n_{f}}\right)-p^{e} S\left(L_{2}\right) L_{2}\right)- \\
&= \beta\left(n_{f} p F\left(\frac{L_{1}}{n_{f}}\right)-n_{f} \Pi\left(p, p F^{\prime}\left(\frac{L_{1}}{n_{f}}\right), \frac{L_{1}}{n_{f}}\right)-(1-\beta) n_{f} \Pi\left(p, p F^{\prime}\left(\frac{L_{2}}{n_{f}}\right), \frac{L_{2}}{n_{f}}\right)\right. \\
& \quad(1-\beta)\left(n_{f} p F\left(\frac{L_{2}}{n_{f}}\right)-n_{f} \Pi\left(p, p F^{\prime}\left(\frac{L_{2}}{n_{f}}\right), \frac{L_{2}}{n_{f}}\right)-L_{1}\right)+ \\
&=\beta\left(p F^{\prime}\left(\frac{L_{1}}{n_{f}}\right) L_{1}-p^{e} S\left(L_{1}\right) L_{2}\right)+(1-\beta)\left(n_{f} p F^{\prime}\left(\frac{L_{2}}{n_{f}}\right) L_{2}-p^{e} S\left(L_{2}\right) L_{2}\right) \\
&=\beta \Omega\left(p^{e}, p F^{\prime}\left(\frac{L_{1}}{n_{f}}\right), L_{1}\right)+(1-\beta) \Omega\left(p^{e}, p F^{\prime}\left(\frac{L_{2}}{n_{f}}\right), L_{2}\right)
\end{aligned}
$$

prove the strict concavity of the payoff frontier in the $(\Pi, \Omega)$ space and thus the convexity of the set feasible payoffs. 


\section{A.2 Proof of Lemma 3.1}

Proof. 1. Let $\left(p^{e}, p\right) \gg 0$ be given.

In the boundary case of no union power $\lambda=0$, the constraint $\Omega\left(\theta^{e}, \alpha, h_{\text {com }}(\alpha)\right) \geq 0$ has to bind, which is equivalent to $N\left(\alpha / \theta^{e}\right)=n_{f} h_{\text {com }}(\alpha)$. Because of the strict monotonicity of the functions $N$ and $h_{\text {com }}$ in $\alpha$ and because of the surjectivity of $N$, this wage uniquely exists. Furthermore, $W_{\text {rtm }}\left(\theta^{e}, 0\right)$ is strictly monotonically increasing in expected inflation $\theta^{e}$.

Let $\lambda>0$. Note first that (4) implies

$$
\frac{\mathrm{d} \Omega\left(\theta^{e}, \alpha, L\right)}{\mathrm{d} \alpha}=\frac{1-\lambda}{\lambda} \frac{\Omega\left(\theta^{e}, \alpha, L\right)}{\Pi\left(1, \alpha, L / n_{f}\right)} L \geq 0,
$$

i. e. for any given expected rate of inflation $\theta^{e}$, union utility is nondecreasing in the real wage rate at a solution $\alpha$ of (4). Differentiating $\partial \widetilde{N P}\left(\alpha, \theta^{e}, \lambda\right) / \partial \alpha$, which is stated in (4), with respect to $\theta^{e}$ and $\lambda$ yields

$$
\begin{aligned}
& \frac{\partial^{2} \widetilde{N P}\left(\alpha, \theta^{e}, \lambda\right)}{\partial \alpha \partial \theta^{e}}=-\frac{\lambda}{\left(\Omega\left(\theta^{e}, \alpha, L\right)\right)^{2}} \underbrace{\frac{\mathrm{d} \Omega\left(\theta^{e}, \alpha, L\right)}{\mathrm{d} \alpha}}_{\geq 0} \underbrace{\frac{\partial \Omega\left(\theta^{e}, \alpha, L\right)}{\partial \theta^{e}}}_{=-S(L) L<0} \widetilde{N P}\left(\alpha, \theta^{e}, \lambda\right) \\
& +\frac{\lambda}{\Omega\left(\theta^{e}, \alpha, L\right)} \underbrace{\frac{\mathrm{d}^{2} \Omega\left(\theta^{e}, \alpha, L\right)}{\mathrm{d} \alpha \mathrm{d} \theta^{e}}}_{=-S_{\mathrm{com}}(L) n_{f} h_{\mathrm{com}}^{\prime}(\alpha)>0} \widetilde{N P}\left(\alpha, \theta^{e}, \lambda\right) \\
& +\underbrace{\left(\frac{\lambda}{\Omega\left(\theta^{e}, \alpha, L\right)} \frac{\mathrm{d} \Omega\left(\theta^{e}, \alpha, L\right)}{\mathrm{d} \alpha}-\frac{1-\lambda}{\Pi\left(1, \alpha, L / n_{f}\right)} L\right)}_{=\frac{\partial \widetilde{N P}\left(\alpha, \theta^{e}, \lambda\right)}{\partial \alpha} \frac{1}{\overline{N P}\left(\alpha, \theta^{e}, \lambda\right)}=0} \frac{\partial \widetilde{N P}\left(\alpha, \theta^{e}, \lambda\right)}{\partial \theta^{e}}>0
\end{aligned}
$$

and

$$
\begin{aligned}
\frac{\partial^{2} \widetilde{N P}\left(\alpha, \theta^{e}, \lambda\right)}{\partial \alpha \partial \lambda}= & \frac{1}{\Omega\left(\theta^{e}, \alpha, L\right)} \underbrace{\frac{\mathrm{d} \Omega\left(\theta^{e}, \alpha, L\right)}{\mathrm{d} \alpha}}_{\geq 0}+\frac{1}{\Pi\left(1, \alpha, L / n_{f}\right)} L) \widetilde{N P}\left(\alpha, \theta^{e}, \lambda\right) \\
& +\underbrace{\left(\frac{\lambda}{\Omega\left(\theta^{e}, \alpha, L\right)} \frac{\mathrm{d} \Omega\left(\theta^{e}, \alpha, L\right)}{\mathrm{d} \alpha}-\frac{1-\lambda}{\Pi\left(1, \alpha, L / n_{f}\right)} L\right)}_{=\frac{\partial \widetilde{N P}\left(\alpha, \theta^{e}, \lambda\right)}{\partial \alpha} \frac{1}{\widehat{N P}\left(\alpha, \theta^{e}, \lambda\right)}=0} \frac{\partial \widetilde{N P}\left(\alpha, \theta^{e}, \lambda\right)}{\partial \lambda}>0 .
\end{aligned}
$$

Due to curvature and optimality of $W_{\text {rtm }}\left(\theta^{e}, \lambda\right)$, the second derivative $\partial^{2} \widetilde{N P}\left(\alpha, \theta^{e}, \lambda\right) / \partial \alpha^{2}<0$ has to be negative. Applying the implicit function theorem to (4) then implies

$$
\frac{\partial W_{\mathrm{rtm}}\left(\theta^{e}, \lambda\right)}{\partial \theta^{e}}=-\frac{\partial^{2} \widetilde{N P}\left(\alpha, \theta^{e}, \lambda\right) / \partial \alpha \partial \theta^{e}}{\partial^{2} \widetilde{N P}\left(\alpha, \theta^{e}, \lambda\right) / \partial \alpha^{2}}>0
$$

as well as

$$
\frac{\partial W_{\mathrm{rtm}}\left(\theta^{e}, \lambda\right)}{\partial \lambda}=-\frac{\partial^{2} \widetilde{N P}\left(\alpha, \theta^{e}, \lambda\right) / \partial \alpha \partial \lambda}{\partial^{2} \widetilde{N P}\left(\alpha, \theta^{e}, \lambda\right) / \partial \alpha^{2}}>0
$$


i. e. $W_{\mathrm{rtm}}\left(\theta^{e}, \lambda\right)$ is strictly monotonically increasing in expected inflation and union power.

2. Because of the upper bound on $\partial^{2} \widetilde{N P}\left(\alpha, \theta^{e}, \lambda\right) / \partial \alpha^{2}$

$$
0<E_{W_{\mathrm{rtm}}}\left(\theta^{e}\right)=\frac{\partial W_{\mathrm{rtm}}\left(\theta^{e}, \lambda\right)}{\partial \theta^{e}} \frac{\theta^{e}}{\alpha}=-\frac{\partial^{2} \widetilde{N P}\left(\alpha, \theta^{e}, \lambda\right) / \partial \alpha \partial \theta^{e}}{\partial^{2} \widetilde{N P}\left(\alpha, \theta^{e}, \lambda\right) / \partial \alpha^{2}} \frac{\theta^{e}}{\alpha}<1
$$

which proves the assertion.

\section{B Calculations Parametric Example - the Isoelastic Case}

The isoelastic form of the production function implies that

$$
\begin{gathered}
F^{\prime}(z)=A z^{B-1}, \quad h_{\mathrm{com}}\left(\frac{w}{p}\right)=\left(F^{\prime}\right)^{-1}\left(\frac{w}{p}\right)=\left(\frac{A}{w / p}\right)^{\frac{1}{1-B}}, \\
\frac{w L}{n_{f} p F\left(L / n_{f}\right)}=\frac{F^{\prime}\left(L / n_{f}\right)\left(L / n_{f}\right)}{F\left(L / n_{f}\right)}=E_{F}\left(\frac{L}{n_{f}}\right)=B, \\
h_{\mathrm{eff}}^{-1}(L)=\frac{F^{\prime}\left(L / n_{f}\right)}{S_{\mathrm{com}}(L)}=A\left(1-\tau_{w}\right) n_{f}^{1-B} n_{w}^{1 / C} L^{-\frac{C(1-B)+1}{C}}, \\
h_{\mathrm{eff}}\left(\theta^{e}\right)=\left(\frac{\theta^{e}}{A\left(1-\tau_{w}\right) n_{f}^{1-B} n_{w}^{1 / C}}\right)^{-\frac{C}{C(1-B)+1}} \\
=A^{\frac{C}{C(1-B)+1}\left(1-\tau_{w}\right)^{\frac{C}{C(1-B)+1}} n_{f}^{\frac{C(1-B)}{C(1-B)+1}} n_{w}^{\frac{1}{C(1-B)+1}}\left(\theta^{e}\right)^{-\frac{C}{C(1-B)+1}} .}
\end{gathered}
$$

Then, for $\left(p^{e}, p\right) \gg 0$ given, the Nash product can be rewritten as

$$
\begin{aligned}
N P(w, L, \lambda) & =\left(n_{f} p F\left(\frac{L}{n_{f}}\right)-w L\right)^{1-\lambda}\left(w L-p^{e} S(L) L\right)^{\lambda} \\
& =n_{f} p F\left(\frac{L}{n_{f}}\right)(1-B)^{1-\lambda}\left(B-\frac{\theta^{e} S(L) L}{n_{f} F\left(L / n_{f}\right)}\right)^{\lambda} \\
& =n_{f} p F\left(\frac{L}{n_{f}}\right)(1-B)^{1-\lambda}\left(B-B \frac{C}{C+1} \frac{\theta^{e} S_{\mathrm{com}}(L)}{F^{\prime}\left(L / n_{f}\right)}\right)^{\lambda} \\
& =n_{f} p F\left(\frac{L}{n_{f}}\right)(1-B)^{1-\lambda} B^{\lambda}\left(1-\frac{C}{C+1} \frac{\theta^{e}}{h_{\mathrm{eff}}^{-1}(L)}\right)^{\lambda},
\end{aligned}
$$

subject to $L=n_{f} h_{\mathrm{com}}(w / p)$. This yields, with $L=n_{f} h_{\mathrm{com}}(w / p)$,

$$
\begin{aligned}
\arg \max _{w \geq 0}\{N P(w, L, \lambda)\} & =\arg \max _{w \geq 0}\left\{n_{f} F\left(\frac{L}{n_{f}}\right)\left(1-\frac{C}{C+1} \frac{\theta^{e}}{h_{\mathrm{eff}}^{-1}(L)}\right)^{\lambda}\right\} \\
& =p \arg \max _{w / p \geq 0}\left\{n_{f} F\left(\frac{L}{n_{f}}\right)\left(1-\frac{C}{C+1} \frac{\theta^{e}}{h_{\mathrm{eff}}^{-1}(L)}\right)^{\lambda}\right\}=p W_{\mathrm{rtm}}\left(\frac{p^{e}}{p}, \lambda\right)
\end{aligned}
$$


The first-order condition for an interior solution then is

$$
\begin{aligned}
0 & =\frac{F^{\prime}\left(L / n_{f}\right)\left(L / n_{f}\right)}{F\left(L / n_{f}\right)}\left(1-\frac{C}{C+1} \frac{\theta^{e}}{h_{\mathrm{eff}}^{-1}(L)}\right)+\lambda \frac{C}{C+1} \frac{\theta^{e}}{h_{\mathrm{eff}}^{-1}(L)} \frac{\left(h_{\mathrm{eff}}^{-1}\right)^{\prime}(L) L}{h_{\mathrm{eff}}^{-1}(L)} \\
& =B-\frac{B C}{C+1} \frac{\theta^{e}}{h_{\mathrm{eff}}^{-1}(L)}+\lambda \frac{B C-(C+1)}{C+1} \frac{\theta^{e}}{h_{\mathrm{eff}}^{-1}(L)} \\
& =B-\frac{B C}{C+1}\left(1+\lambda \frac{C(1-B)+1}{B C}\right) \frac{\theta^{e}}{h_{\mathrm{eff}}^{-1}(L)}
\end{aligned}
$$

or

$$
h_{\mathrm{eff}}\left(\frac{C}{C+1}\left(1+\lambda \frac{C(1-B)+1}{B C}\right) \theta^{e}\right)=L=n_{f} h_{\mathrm{com}}\left(\frac{w}{p}\right)
$$

which is equivalent to

$$
\begin{aligned}
\frac{w}{p} & =F^{\prime}\left(\frac{1}{n_{f}} h_{\mathrm{eff}}\left(\frac{C}{C+1}\left(1+\lambda \frac{C(1-B)+1}{B C}\right) \theta^{e}\right)\right) \\
& =\left(n_{f}\right)^{1-B}\left(\frac{C}{C+1}\left(1+\lambda \frac{C(1-B)+1}{B C}\right)\right)^{\frac{C(1-B)}{C(1-B)+1}} F^{\prime}\left(h_{\mathrm{eff}}\left(\theta^{e}\right)\right) \\
& =A\left(n_{f}\right)^{1-B}\left(\frac{C}{C+1}\left(1+\lambda \frac{C(1-B)+1}{B C}\right)\right)^{\frac{C(1-B)}{C(1-B)+1}}\left(h_{\mathrm{eff}}\left(\theta^{e}\right)\right)^{B-1} \\
& =A^{\frac{1}{C(1-B)+1}}\left(\frac{n_{f}}{n_{w}}\right)^{\frac{1-B}{C(1-B)+1}}\left(\frac{C}{C+1}\left(1+\lambda \frac{C(1-B)+1}{B C}\right) \frac{1}{1-\tau_{w}} \theta^{e}\right)^{\frac{C(1-B)}{C(1-B)+1}} \\
& =W_{\mathrm{rtm}}\left(\theta^{e}, \lambda\right) .
\end{aligned}
$$

The real wage $W_{\mathrm{rtm}}\left(\theta^{e}, \lambda\right)$ is an isoelastic function in expected inflation with

$$
0<E_{W_{\mathrm{rtm}}}\left(\theta^{e}\right)=\frac{C(1-B)}{C(1-B)+1}<1,
$$

i. e. $W_{\mathrm{rtm}}\left(\theta^{e}, \lambda\right)$ is strictly monotonically increasing, globally invertible and strictly concave with respect to $p^{e} / p$. For $\lambda>0$

$$
0<E_{W_{\mathrm{rtm}}}(\lambda)=\frac{\lambda \frac{C(1-B)+1}{B C}}{1+\lambda \frac{C(1-B)+1}{B C}} \frac{C(1-B)}{C(1-B)+1}<\frac{C(1-B)}{C(1-B)+1}=E_{W_{\mathrm{rtm}}}\left(\theta^{e}\right)<1
$$

implies that $W_{\mathrm{rtm}}\left(\theta^{e}, \lambda\right)$ is strictly monotonically increasing and strictly concave with respect to $\lambda$.

Since the production function and the firms' labor demand are as well isoelastic, the aggregate supply function

$$
A S_{\mathrm{rtm}}\left(\theta^{e}, \lambda\right)=n_{f} F\left(h_{\mathrm{com}}\left(W_{\mathrm{rtm}}\left(\theta^{e}, \lambda\right)\right)\right)
$$

is isoelastic with an elasticity

$$
\begin{aligned}
0>E_{A S_{\mathrm{rtm}}}\left(\theta^{e}\right) & =E_{F}(z) E_{h_{\mathrm{com}}}(\alpha) E_{W_{\mathrm{rtm}}}\left(\theta^{e}\right)=B \frac{1}{B-1} \frac{C(1-B)}{C(1-B)+1} \\
& =-\frac{B C}{C(1-B)+1}>-1
\end{aligned}
$$


and $0>E_{A S_{\mathrm{rtm}}}(\lambda)>E_{A S_{\mathrm{rtm}}}\left(\theta^{e}\right)>-1$. Therefore, the elasticity of the price law with respect to bargaining power is bounded by unity, i. e.

$$
0<E_{\mathcal{P}_{\mathrm{rtm}}}(\lambda)=\frac{-E_{A S_{\mathrm{rtm}}}(\lambda)}{-E_{A S_{\mathrm{rtm}}}\left(\theta^{e}\right)+E_{D_{\mathrm{rtm}}}(m)}<\frac{-E_{A S_{\mathrm{rtm}}}\left(\theta^{e}\right)}{-E_{A S_{\mathrm{rtm}}}\left(\theta^{e}\right)+E_{D_{\mathrm{rtm}}}(m)}<1 .
$$

\section{B.1 Comparative Statics}

Since several partial derivatives are zero under isoelastic production and disutility functions, the missing comparative-statics effects can be calculated.

Aggregate returns (i. e. gross national product) are increasing with respect to all state variables.

$$
\begin{aligned}
E_{\mathcal{P}_{\mathrm{rtm}}}\left(p^{e}\right)+E_{\mathcal{Y}_{\mathrm{rtm}}}\left(p^{e}\right) & =E_{\mathcal{P}_{\mathrm{rtm}}}\left(p^{e}\right)\left(1-E_{A S_{\mathrm{rtm}}}\left(\theta^{e}\right)\right)+E_{A S_{\mathrm{rtm}}}\left(\theta^{e}\right) \\
& =E_{\mathcal{P}_{\mathrm{rtm}}}\left(p^{e}\right)\left(1-E_{D_{\mathrm{rtm}}}(m)\right) \in(0,1) \\
E_{\mathcal{P}_{\mathrm{rtm}}}(\lambda)+E_{\mathcal{Y}_{\mathrm{rtm}}}(\lambda) & =E_{\mathcal{P}_{\mathrm{rtm}}}(\lambda)\left(1-E_{A S_{\mathrm{rtm}}}\left(\theta^{e}\right)\right)+E_{A S_{\mathrm{rtm}}}(\lambda) \\
& =E_{\mathcal{P}_{\mathrm{rtm}}}(\lambda)\left(1-E_{D_{\mathrm{rtm}}}(m)\right) \in(0,1)
\end{aligned}
$$

Again, all elasticities are bounded by unity. Since aggregate nominal profits and the wage bill are constant multiples of aggregate returns, i. e.

$$
\mathcal{W}_{\mathrm{rtm}}\left(M, p^{e}, \lambda\right) \mathcal{L}_{\mathrm{rtm}}\left(M, p^{e}, \lambda\right)=B \mathcal{P}_{\mathrm{rtm}}\left(M, p^{e}, \lambda\right) \mathcal{Y}_{\mathrm{rtm}}\left(M, p^{e}, \lambda\right)
$$

resp.

$$
\Pi_{\mathrm{rtm}}\left(M, p^{e}, \lambda\right)=(1-B) \mathcal{P}_{\mathrm{rtm}}\left(M, p^{e}, \lambda\right) \mathcal{Y}_{\mathrm{rtm}}\left(M, p^{e}, \lambda\right)
$$

their elasticities are the same as the ones of aggregate returns, i. e.

$$
\begin{aligned}
E_{\Pi_{\mathrm{rtm}}}(M) & =E_{\mathcal{W}_{\mathrm{rtm}}}(M)+E_{\mathcal{L}_{\mathrm{rtm}}}(M)=E_{\mathcal{P}_{\mathrm{rtm}}}(M)+E_{\mathcal{Y}_{\mathrm{rtm}}}(M) \in(0,1) \\
E_{\Pi_{\mathrm{rtm}}}\left(p^{e}\right) & =E_{\mathcal{W}_{\mathrm{rtm}}}\left(p^{e}\right)+E_{\mathcal{L}_{\mathrm{rtm}}}\left(p^{e}\right)=E_{\mathcal{P}_{\mathrm{rtm}}}\left(p^{e}\right)+E_{\mathcal{Y}_{\mathrm{rtm}}}\left(p^{e}\right) \in(0,1) \\
E_{\Pi_{\mathrm{rtm}}}(\lambda) & =E_{\mathcal{W}_{\mathrm{rtm}}}(\lambda)+E_{\mathcal{L}_{\mathrm{rtm}}}(\lambda)=E_{\mathcal{P}_{\mathrm{rtm}}}(\lambda)+E_{\mathcal{Y}_{\mathrm{rtm}}}(\lambda) \in(0,1)
\end{aligned}
$$

i. e. the wage bill and nominal profits are increasing in all state variables, whereas real profits

$$
\frac{\Pi_{\mathrm{rtm}}\left(M, p^{e}, \lambda\right)}{\mathcal{P}_{\mathrm{rtm}}\left(M, p^{e}, \lambda\right)}=(1-B) \mathcal{Y}_{\mathrm{rtm}}\left(M, p^{e}, \lambda\right)
$$

are increasing in $M$, but decreasing in $p^{e}$ and in $\lambda$ because of the resp. changes in the employment level. This implies that young consumers earn more, but consume less if $\lambda$ increases. Due to the price increase, old consumers can afford less units of the commodity and the government needs to spend more to finance its consumption level $g$. Therefore, all groups of consumers suffer from reduced consumption.

Concerning the net wage bill, first note that

$$
\begin{aligned}
E_{\mathcal{L}_{\mathrm{rtm}}}(M) & =-E_{h_{\mathrm{com}}} E_{W_{\mathrm{rtm}}}\left(\theta^{e}\right) E_{\mathcal{P}_{\mathrm{rtm}}}(M)=\frac{C}{C(1-B)+1} E_{\mathcal{P}_{\mathrm{rtm}}}(M) \\
& >\frac{C}{C(1-B)+1} \frac{1}{\frac{B C}{C(1-B)+1}+1}=\frac{C}{C+1}
\end{aligned}
$$


and

$$
\begin{aligned}
E_{\mathcal{L}_{\mathrm{rtm}}}\left(p^{e}\right) & =E_{h_{\mathrm{com}}} E_{W_{\mathrm{rtm}}}\left(\theta^{e}\right)\left(1-E_{\mathcal{P}_{\mathrm{rtm}}}\left(p^{e}\right)\right)=-\frac{C}{C(1-B)+1}\left(1-E_{\mathcal{P}_{\mathrm{rtm}}}\left(p^{e}\right)\right) \\
& >-\frac{C}{C(1-B)+1}\left(1-\frac{\frac{B C}{C(1-B)+1}}{\frac{B C}{C(1-B)+1}+1}\right)=-\frac{C}{C+1} .
\end{aligned}
$$

Then

$$
\begin{aligned}
& E_{\boldsymbol{\Omega}_{\mathrm{rtm}}}(M)=\frac{\mathcal{L}_{\mathrm{rtm}}}{\Omega} E_{\mathcal{P}_{\mathrm{rtm}}}(M) \mathcal{P}_{\mathrm{rtm}} F^{\prime}\left(\frac{\mathcal{L}_{\mathrm{rtm}}}{n_{f}}\right) \\
& +\frac{\mathcal{L}_{\mathrm{rtm}}}{\Omega} E_{\mathcal{L}_{\mathrm{rtm}}}(M)\left(B \mathcal{P}_{\mathrm{rtm}} F^{\prime}\left(\frac{\mathcal{L}_{\mathrm{rtm}}}{n_{f}}\right)-\frac{C+1}{C} p^{e} S\left(\mathcal{L}_{\mathrm{rtm}}\right)\right) \\
& =\frac{\mathcal{L}_{\mathrm{rtm}}}{\Omega} E_{\mathcal{L}_{\mathrm{rtm}}}(M) \frac{C(1-B)+1}{C} \mathcal{W}_{\mathrm{rtm}} \\
& +\frac{\mathcal{L}_{\mathrm{rtm}}}{\Omega} E_{\mathcal{L}_{\mathrm{rtm}}}(M)\left(B \mathcal{W}_{\mathrm{rtm}}-\frac{C+1}{C} p^{e} S\left(\mathcal{L}_{\mathrm{rtm}}\right)\right) \\
& =\frac{\mathcal{L}_{\mathrm{rtm}}}{\Omega} E_{\mathcal{L}_{\mathrm{rtm}}}(M) \frac{C+1}{C}\left(\mathcal{W}_{\mathrm{rtm}}-p^{e} S\left(\mathcal{L}_{\mathrm{rtm}}\right)\right)=\frac{C+1}{C} E_{\mathcal{L}_{\mathrm{rtm}}}(M) \in(0,1) \\
& E_{\boldsymbol{\Omega}_{\mathrm{rtm}}}\left(p^{e}\right)=\frac{p^{e}}{\Omega}\left(E_{\mathcal{P}_{\mathrm{rtm}}}\left(p^{e}\right) \frac{\mathcal{P}_{\mathrm{rtm}}}{p^{e}} F^{\prime}\left(\frac{\mathcal{L}_{\mathrm{rtm}}}{n_{f}}\right) \mathcal{L}_{\mathrm{rtm}}-S\left(\mathcal{L}_{\mathrm{rtm}}\right) \mathcal{L}_{\mathrm{rtm}}\right) \\
& +\frac{\mathcal{L}_{\mathrm{rtm}}}{\Omega} E_{\mathcal{L}_{\mathrm{rtm}}}\left(p^{e}\right)\left(B \mathcal{P}_{\mathrm{rtm}} F^{\prime}\left(\frac{\mathcal{L}_{\mathrm{rtm}}}{n_{f}}\right)-\frac{C+1}{C} S\left(\mathcal{L}_{\mathrm{rtm}}\right)\right) \\
& =\frac{\mathcal{L}_{\mathrm{rtm}}}{\Omega}\left(\left(\frac{C(1-B)+1}{C} E_{\mathcal{L}_{\mathrm{rtm}}}\left(p^{e}\right)+1\right) \mathcal{W}_{\mathrm{rtm}}-p^{e} S\left(\mathcal{L}_{\mathrm{rtm}}\right)\right) \\
& +\frac{\mathcal{L}_{\mathrm{rtm}}}{\Omega} E_{\mathcal{L}_{\mathrm{rtm}}}\left(p^{e}\right)\left(B \mathcal{W}_{\mathrm{rtm}}-\frac{C+1}{C} S\left(\mathcal{L}_{\mathrm{rtm}}\right)\right) \\
& =1+\frac{\mathcal{L}_{\mathrm{rtm}}}{\Omega} E_{\mathcal{L}_{\mathrm{rtm}}}\left(p^{e}\right)\left(\frac{C(1-B)+1}{C} \mathcal{W}_{\mathrm{rtm}}+B \mathcal{W}_{\mathrm{rtm}}-\frac{C+1}{C} S\left(\mathcal{L}_{\mathrm{rtm}}\right)\right) \\
& =1+\frac{C+1}{C} E_{\mathcal{L}_{\mathrm{rtm}}}\left(p^{e}\right) \in(0,1)
\end{aligned}
$$

The net wage bill is increasing with respect to union power because the wage bill is increasing whereas the reservation wage is decreasing, i. e.

$$
E_{\Omega_{\mathrm{rtm}}}(\lambda)>0
$$

Concerning the comparative statics under efficient bargaining, first note that

$$
E_{\mathcal{P}_{\mathrm{eff}}}(M)=\frac{E_{D_{\mathrm{eff}}}(m)}{-E_{A S_{\mathrm{eff}}}\left(\theta^{e}\right)+E_{D_{\mathrm{eff}}}(m)}<\frac{1}{1-E_{A S_{\mathrm{eff}}}\left(\theta^{e}\right)}
$$

and

$$
E_{\mathcal{P}_{\mathrm{eff}}}\left(p^{e}\right)=\frac{-E_{A S_{\mathrm{eff}}}\left(\theta^{e}\right)}{-E_{A S_{\mathrm{eff}}}\left(\theta^{e}\right)+E_{D_{\mathrm{eff}}}(m)}>\frac{-E_{A S_{\mathrm{eff}}}\left(\theta^{e}\right)}{1-E_{A S_{\mathrm{eff}}}\left(\theta^{e}\right)},
$$


which implies that

$$
E_{\mathcal{P}_{\text {eff }}}(M)+E_{\mathcal{Y}_{\text {eff }}}(M)=\left(1-E_{A S_{\text {eff }}}\left(\theta^{e}\right)\right) E_{\mathcal{P}_{\text {eff }}}(M) \in(0,1)
$$

and

$$
E_{\mathcal{P}_{\text {eff }}}\left(p^{e}\right)+E_{\mathcal{Y}_{\text {eff }}}\left(p^{e}\right)=E_{A S_{\text {eff }}}\left(\theta^{e}\right)+\left(1-E_{A S_{\text {eff }}}\left(\theta^{e}\right)\right) E_{\mathcal{P}_{\text {eff }}}\left(p^{e}\right) \in(0,1)
$$

holds. Since the wage bill and nominal profits are constant multiples of aggregate returns, i.e.

$$
\mathcal{W}_{\mathrm{eff}}\left(M, p^{e}, \lambda\right) \mathcal{L}_{\mathrm{eff}}\left(M, p^{e}, \lambda\right)=\left(\frac{B C}{C+1}+\lambda \frac{C(1-B)+1}{C+1}\right) \mathcal{P}_{\mathrm{eff}}\left(M, p^{e}, \lambda\right) \mathcal{Y}_{\mathrm{eff}}\left(M, p^{e}, \lambda\right)
$$

resp.

$$
\Pi_{\mathrm{eff}}\left(M, p^{e}, \lambda\right)=(1-\lambda) \frac{C(1-B)+1}{C+1} \mathcal{P}_{\mathrm{eff}}\left(M, p^{e}, \lambda\right) \mathcal{Y}_{\mathrm{eff}}\left(M, p^{e}, \lambda\right)
$$

one can state that

$$
E_{\mathcal{W}_{\text {eff }}}(M)+E_{\mathcal{L}_{\text {eff }}}(M)=E_{\Pi_{\text {eff }}}(M)=E_{\mathcal{P}_{\text {eff }}}(M)+E_{\mathcal{Y}_{\text {eff }}}(M) \in(0,1)
$$

and

$$
E_{\mathcal{W}_{\mathrm{eff}}}\left(p^{e}\right)+E_{\mathcal{L}_{\mathrm{eff}}}\left(p^{e}\right)=E_{\boldsymbol{\Pi}_{\mathrm{eff}}}\left(p^{e}\right)=E_{\mathcal{P}_{\mathrm{eff}}}\left(p^{e}\right)+E_{\mathcal{Y}_{\mathrm{eff}}}\left(p^{e}\right) \in(0,1) .
$$

The effect of changes of money holdings and price expectations on the net wage bill $\Omega_{\mathrm{eff}}\left(M, p^{e}, \lambda\right)$ can also be calculated.

$$
\begin{aligned}
& E_{\boldsymbol{\Omega}_{\mathrm{eff}}}(M)=\frac{1}{\Omega}\left(E_{\mathcal{W}_{\mathrm{eff}} \mathcal{L}_{\mathrm{eff}}}(M) \mathcal{W}_{\mathrm{eff}} \mathcal{L}_{\mathrm{eff}}-E_{p^{e} S\left(\mathcal{L}_{\mathrm{eff}}\right) \mathcal{L}_{\mathrm{eff}}}(M) p^{e} S\left(\mathcal{L}_{\mathrm{eff}}\right) \mathcal{L}_{\mathrm{eff}}\right) \\
& =\frac{1}{\Omega}\left(\left(1-E_{A S_{\text {eff }}}\left(\theta^{e}\right)\right) E_{\mathcal{P}_{\text {eff }}}(M) \mathcal{W}_{\text {eff }} \mathcal{L}_{\text {eff }}+\frac{C+1}{C} E_{h_{\text {eff }}}\left(\theta^{e}\right) E_{\mathcal{P}_{\text {eff }}}(M) p^{e} S\left(\mathcal{L}_{\text {eff }}\right) \mathcal{L}_{\text {eff }}\right) \\
& =\frac{1}{\Omega}(\left(1-E_{A S_{\mathrm{eff}}}\left(\theta^{e}\right)\right) \mathcal{W}_{\mathrm{eff}} \mathcal{L}_{\mathrm{eff}}-\underbrace{\frac{C+1}{C(1-B)+1}}_{=1-E_{A S_{\mathrm{eff}}}\left(\theta^{e}\right)} p^{e} S\left(\mathcal{L}_{\mathrm{eff}}\right) \mathcal{L}_{\mathrm{eff}}) E_{\mathcal{P}_{\mathrm{eff}}}(M) \\
& =\left(1-E_{A S_{\text {eff }}}\left(\theta^{e}\right)\right) E_{\mathcal{P}_{\text {eff }}}(M) \in(0,1) \\
& E_{\boldsymbol{\Omega}_{\mathrm{eff}}}\left(p^{e}\right)=\frac{1}{\Omega}\left(E_{\mathcal{W}_{\mathrm{eff}} \mathcal{L}_{\mathrm{eff}}}\left(p^{e}\right) \mathcal{W}_{\mathrm{eff}} \mathcal{L}_{\mathrm{eff}}-E_{p^{e} S\left(\mathcal{L}_{\mathrm{eff}}\right) \mathcal{L}_{\mathrm{eff}}}\left(p^{e}\right) p^{e} S\left(\mathcal{L}_{\mathrm{eff}}\right) \mathcal{L}_{\mathrm{eff}}\right) \\
& =\frac{1}{\Omega}\left(\left(E_{A S_{\mathrm{eff}}}\left(\theta^{e}\right)+\left(1-E_{A S_{\mathrm{eff}}}\left(\theta^{e}\right)\right) E_{\mathcal{P}_{\mathrm{eff}}}\left(p^{e}\right)\right) \mathcal{W}_{\mathrm{eff}} \mathcal{L}_{\mathrm{eff}}\right. \\
& \left.-\left(1-\frac{C+1}{C(1-B)+1}\left(1-E_{\mathcal{P}_{\text {eff }}}\left(p^{e}\right)\right)\right) p^{e} S\left(\mathcal{L}_{\text {eff }}\right) \mathcal{L}_{\text {eff }}\right) \\
& =\frac{1}{\Omega}\left(\left(E_{A S_{\mathrm{eff}}}\left(\theta^{e}\right)+\left(1-E_{A S_{\mathrm{eff}}}\left(\theta^{e}\right)\right) E_{\mathcal{P}_{\mathrm{eff}}}\left(p^{e}\right)\right) \mathcal{W}_{\mathrm{eff}} \mathcal{L}_{\mathrm{eff}}\right. \\
& \left.-\left(E_{A S_{\mathrm{eff}}}\left(\theta^{e}\right)+\left(1-E_{A S_{\mathrm{eff}}}\left(\theta^{e}\right)\right) E_{\mathcal{P}_{\mathrm{eff}}}\left(p^{e}\right)\right) p^{e} S\left(\mathcal{L}_{\mathrm{eff}}\right) \mathcal{L}_{\mathrm{eff}}\right) \\
& =E_{A S_{\mathrm{eff}}}\left(\theta^{e}\right)+\left(1-E_{A S_{\mathrm{eff}}}\left(\theta^{e}\right)\right) E_{\mathcal{P}_{\mathrm{eff}}}\left(p^{e}\right) \in(0,1)
\end{aligned}
$$




\section{References}

Blanchard, O. J. \& S. Fischer (1993): Lectures on Macroeconmics. The MIT Press, Cambridge, Mass. a.o., Seventh Printing.

Böнm, V. (2010): "Macroeconomic Theory", Lecture Notes, Department of Economics, Bielefeld University, Bielefeld.

Böhm, V. \& O. ClaAs (2012): "Efficient Wage Bargaining in a Dynamic Macroeconomic Model", Working Paper 465, Bielefeld University, Center for Mathematical Economics.

Böhm, V., T. Pampel \& J. Wenzelburger (2005): "On the Stability of Balanced Growth", Discussion Paper No. 548, Department of Economics, Bielefeld University, Bielefeld.

Boотн, A. L. (1996): The economics of the trade union. Cambridge Univ. Pr., Cambridge a.o.

Deardorff, A. V. (1970): "Growth Paths in the Solow Neoclassical Growth Model", Quarterly Journal of Economics, 84(1), 134-139.

LAyard, P. R. G. \& S. J. Nickell (1990): "Is Unemployment Lower if Unions Bargain over Employment?", The Quarterly Journal of Economics, 105(3), 773-787.

Layard, P. R. G., S. J. Nickell \& R. Jackman (2009): Unemployment. Macroeconomic performance and the labour market. Oxford Univ. Press, Oxford a.o.

Leontief, W. (1946): "The Pure Theory of the Guaranteed Annual Wage Contract", Journal of Political Economy, 54(1), 76-79.

McDonald, I. M. \& R. M. Solow (1981): "Wage Bargaining and Employment", The American Economic Review, 71(5), 896-908.

NAsh, J. F. (1950): “The Bargaining Problem", Econometrica, 18(2), 155-162.

(1953): "Two-Person Cooperative Games", Econometrica, 21(1), 128-140.

Pampel, T. (2009): "On the Dynamics of Basic Growth Models: Ratio Stability vs. Convergence and Divergence in State Space", German Economic Review, 10(4), 384-400. 